This paper was published in Applied Optics and is made available as an electronic reprint with the permission of OSA. The paper can be found at the following URL on the OSA website: http://www.opticsinfobase.org/ao/abstract.cfm?uri=ao-47-14-2660. Systematic or multiple reproduction or distribution to multiple locations via electronic or other means is prohibited and is subject to penalties under law.

\title{
Biogeo-optics: particle optical properties and the partitioning of the spectral scattering coefficient of ocean waters
}

\author{
Robert H. Stavn $n^{1, t}$ and Scott J. Richter ${ }^{2}$ \\ 'Department of Biology, The University of North Carolina at Greensboro, Greensboro, North Carolina 27402, USA \\ ${ }^{2}$ Department of Mathematics and Statistics, The University of North Carolina at Greensboro, \\ Greensboro, North Carolina 27402, USA \\ *Corresponding author: stavnr@uncg.edu
}

Received 1 October 2007; revised 22 March 2008; accepted 14 April 2008;

posted 14 April 2008 (Doc. ID 87627); published 7 May 2008

\begin{abstract}
We propose a direct method of partitioning the particulate spectral scattering coefficient of the marine hydrosol based on the concurrent determination of the concentrations of particulate mineral and organic matter (the total mass of optically active scattering material exclusive of water) with the particulate spectral scattering coefficient. For this we derive a Model II multiple linear regression model. The multiple linear regression of the particulate spectral scattering coefficient against the independent variables, the concentrations of particulate inorganic matter and particulate organic matter, yields their massspecific spectral scattering cross sections. The mass-specific spectral scattering cross section is simply the particle scattering cross section normalized to the particle mass, a fundamental optical efficiency parameter for the attenuation of electromagnetic radiation [Absorption and Scattering of Light by Small Particles, (Wiley-Interscience, 1983), pp. 80-81, 289]. It is possible to infer the optical properties of the suspended matter from the mass-specific spectral scattering cross sections. From these cross sections we partition the particulate spectral scattering coefficient into its major components. (C) 2008 Optical Society of America
\end{abstract}

OCIS codes: $\quad 010.4450,010.4458,290.5850,280.1415,280.4991,010.4455$.

\section{Introduction}

The scattering coefficient of the marine hydrosol is both the source of remote sensing information about the ocean and the basis for mechanistic inversion algorithms. Such algorithms invert the remote sensing reflectance to retrieve concentrations of materials of interest: suspended sediments, chlorophyll, organic matter, and suspended organic detritus [1]. The absorption coefficient of the marine hydrosol is routinely coupled with the scattering coefficient to generate such remote sensing inversion algorithms [2]. The absorption coefficient is partitioned by various methods into absorption due to phytoplankton, yellow substance, and organic detritus to give more

0003-6935/08/142660-20\$15.00/0

(C) 2008 Optical Society of America information about the materials dissolved and suspended in the marine hydrosol $[3,4]$. It is thus routine to partition the hydrosol absorption coefficient in ocean optics but not the scattering and backscattering coefficients.

The hydrosol scattering coefficient is occasionally partitioned into a molecular water component and a vaguely defined category called "suspended particles." The problem with this approach is that suspended particulate matter can be broadly classified into inorganic matter (often terrigenous) and organic matter (some terrigenous, but usually autochthonous). The two broad categories of suspended particulates have different indices of refraction, essentially nonoverlapping according to available theoretical calculations [5], and therefore rather different scattering coefficients. There are, however, 
very few data on the refractive index of nonliving organic particles. The differing scattering coefficients generate rather different effects on the remote sensing reflectance because the mineral matter, with its relatively high index of refraction, dominates the optical scattering process. This factor is most pronounced in coastal ocean waters and the program we are developing in biogeo-optics will make contributions to coastal ocean remote sensing algorithms by the accurate partitioning of the hydrosol scattering coefficient. As we get further away from the coastline and approach the continental shelf break, the mineral matter will tend to become seasonal in its effects [6,7].

The biogeo-optical approach, though most important for the coastal ocean, can also be a factor in the open ocean, usually assumed bio-optical in nature, when dust storms deposit mineral matter [8-10]. Additionally during blooms both in the open ocean and near-coastal waters, coccolithophores shed quantitative amounts of $\mathrm{CaCO}_{3}$ lith plates, easily visible to satellites, that radically alter the open ocean optical environment [11]. Chlorophyll concentration in the open ocean, typically assumed to covary with the concentration of suspended organic matter, is used to estimate the particle scattering coefficient where the majority of the suspended particles are organic in nature $[12,13]$. However, recent modeling work implicates suspended mineral matter as a factor in the scattering coefficient of the open ocean [14] such as under the above-enumerated conditions.

The ability to partition the particulate scattering and backscattering coefficients becomes very important in the coastal region where the presence of suspended sediment renders chlorophyll retrieval algorithms based on the absorption and backscattering coefficients nearly useless and very limited geographically [15-18]. Furthermore retrieving the concentration of the mineral matter itself is very important as the issues of erosion and loss of the coastal shoreline, the concomitant loss of protective, productive wetlands, and the possible roles of suspended sediments in adsorption of nutrients and pollutants become more important.

Various indirect methods to partition the particulate scattering coefficient have been proposed. Stavn and Keen [19] and Keen and Stavn [20] did this on the basis of a biogeo-optical model in which the majority of hydrosol absorption was ascribed to chlorophyll or CDOM while total scattering was ascribed primarily to mineral matter. This particular approach works best when the mineral matter is suspended quartz or calcite particles. Absorption by mineral matter [21] is easily factored in. The partitioning of the particle scattering coefficient came from knowledge of the total particle scattering coefficient and the calculation of the mineral concentration from physical models of sediment resuspension. The concentration and the particle size distribution (PSD) obtained from the model were utilized in Mie calculations to estimate the mineral particle scatter- ing coefficient. Additionally, complex nonlinear optimizations have been performed utilizing information on the remote sensing reflectance and the concentrations of major inorganic and organic suspended particulates of the aquatic and marine hydrosol [18]. Another indirect method is to estimate the particle scattering coefficient from Kirk [22] relations utilizing the diffuse exponential decay coefficient $K$. Then the estimated total particle scattering coefficient is multiply regressed with the concentration of suspended mineral matter and chlorophyll concentration to get mass-specific mineral optical scattering cross sections $[15,23]$ and thus a partitioning of the indirectly determined particulate scattering coefficient. There have been attempts to build up a scattering coefficient of the marine hydrosol by estimating scattering cross sections for major particulate components, multiplying the cross sections by estimated particle concentrations and assumed size distributions, and adding them together to get a scattering coefficient [24]. Overall this method is sound and well-considered. It does require extensive knowledge of the optical particle types, their concentrations, and their PSDs. At this point their assumptions about the PSD of oceanic particulates are questionable [25]. The modeling accomplished so far does yield approximate relations that are testable hypotheses about the interaction of particle optical properties and bulk optical properties.

We consider the partitioning of the particle scattering coefficient first by reviewing the theory of particle optical properties and the particle scattering cross section as they relate to the bulk particulate scattering coefficient. Then we discuss the mass-specific particle scattering cross section as a simple function of the single particle scattering cross section. From the biogeo-optical mode of analysis, we propose a direct method of partitioning the particulate scattering coefficient. The method utilizes concurrent information on the mass concentration of suspended mineral matter, the particulate inorganic matter (PIM), the mass concentration of suspended organic matter, the particulate organic matter (POM), and the total particulate scattering coefficient. The concentrations of PIM and POM are determined by the loss on ignition (LOI) technique [26], while the total particulate scattering coefficient is determined by the WET Labs AC $9 \mathrm{~m}$ or a similar instrument. The concentrations of PIM and POM are regressed against the total particle scattering coefficient. The partial regression coefficients from this multiple linear regression are then mass-specific scattering cross sections for the PIM and the POM. When the correlation between these three field variables is not high (for example, $R^{2} \approx 0.40$ ), the interpretation of the partial regression slopes becomes ambiguous. There are then two possible regression slopes per independent variable. In univariate Model II regression (one independent variable and one dependent variable), the solution to this problem is to use the geometric mean of the two possible regression slopes as a best esti- 
mate of that slope. We generalize the univariate Model II regression to the multivariate case and illustrate it with data from the northern Gulf of Mexico of both relatively high and relatively low correlation between the particulate scattering coefficient and PIM and POM. Finally we utilize the information on the mass-specific scattering cross sections and the PIM and POM concentrations to partition the total particle scattering coefficient into the scattering coefficient of the suspended mineral particles and the scattering coefficient of the suspended organic particles. This fundamental direct partitioning of the scattering coefficient can be subdivided even further as knowledge of the optics and concentrations of individual mineral and organic components becomes available from laboratory studies and from oceanographic field exercises $[\underline{14}, 27]$.

\section{Particle Optical Properties: Theory}

We wish to demonstrate that the mass-specific spectral scattering cross section of the suspended particulate mineral or organic matter is a simple function of the fundamental optical properties of an individual particle. Gordon and $\mathrm{Du}$ [28], Bohren and Huffman [29], and McCartney [30] point out that the fundamental scattering interaction of a particle with electromagnetic radiation is the differential scattering cross section $d \sigma(\theta) / d \Omega$. Here $d \sigma$ is the cross sectional area of the incoming wave front that is diverted into angle $\theta$, the angular trajectory of radiant power scattered by a particle from a wave front or reference beam, and $d \Omega$ is the solid angle subtended by the radiant power scattered into that trajectory. The total scattering cross section of the particle, $\sigma$, is obtained from the following integral:

$$
\sigma=2 \pi \int_{0}^{\pi}\left(\frac{d \sigma(\theta)}{d \Omega}\right) \sin \theta d \theta
$$

which then represents the total cross sectional area of the particle that is actively interacting with and scattering power from an incoming wave front of electromagnetic radiation. If the incoming wave front is of unit energy per square meter, then $\sigma$ is numerically equal to the total radiant power scattered by the single particle [30] in all directions. And, of course, the scattering cross section is a function of wavelength, which we have not emphasized to keep the notation simple. The scattering activity of a single particle is related to the bulk scattering coefficient per unit volume of a hydrosol containing a given concentration of these particles [28] by

$$
b_{p}(\lambda)=\sum_{i} \sigma_{i}(\lambda) N_{i},
$$

where, assuming that the summation in Eq. (1) is for two particle types, mineral and organic $(i=\overline{2}), b_{p}(\lambda)$ is the particle scattering coefficient at wavelength $\lambda$ per unit volume of hydrosol, and $N_{i}$ is the number of particles of species $i$ per $\mathrm{m}^{3}$. Furthermore assuming the mineral and organic particles are each of one size and composition, the two particle types each possess a particle scattering cross section and

$$
\begin{gathered}
b_{m}(\lambda)=\sigma_{m}(\lambda) N_{m}, \\
b_{o}(\lambda)=\sigma_{o}(\lambda) N_{o},
\end{gathered}
$$

where $b_{m}(\lambda)$ is the mineral particle scattering coefficient at wavelength $\lambda$ per unit hydrosol volume, $\sigma_{m}(\lambda)$ is the single particle scattering cross section at wavelength $\lambda$ of the suspended mineral particles of concentration $N_{m}$ particles $\mathrm{m}^{-3}, b_{o}(\lambda)$ is the organic particle scattering coefficient at wavelength $\lambda$ per unit hydrosol volume, and $\sigma_{o}(\lambda)$ is the single particle scattering cross section at wavelength $\lambda$ of the suspended organic particles of concentration $N_{o}$ particles $\mathrm{m}^{-3}$. The particle scattering coefficient is then partitioned into mineral and organic particle components:

$$
b_{p}(\lambda)=b_{m}(\lambda)+b_{o}(\lambda) .
$$

The particle number concentration, or density, is related to the particle mass concentration by

$$
N_{m}=V_{\mathrm{Tm}} / \nu_{m},
$$

where $V_{\mathrm{Tm}}$ is the volume proportion of the total suspended mineral particles in a cubic meter of hydrosol and $\nu_{m}$ is the volume of a single mineral particle. Note that $V_{\mathrm{Tm}}$ is therefore dimensionless [5]. Thus

$$
\mathrm{PIM}=\rho_{m} V_{\mathrm{Tm}}=N_{m} \rho_{m} \nu_{m},
$$

where $\rho_{m}$ is the density or mass per unit volume $\left(\mathrm{g} \mathrm{m}^{-3}\right)$ of the mineral particle, and PIM is the mass concentration or total mass of the mineral particles in a unit volume of hydrosol, so

$$
\begin{gathered}
N_{m}=\left(\frac{1}{\rho_{m} \nu_{m}}\right) \mathrm{PIM}, \quad b_{m}(\lambda)=\left(\frac{\sigma_{m}(\lambda)}{\rho_{m} \nu_{m}}\right) \mathrm{PIM}, \\
\sigma_{\mathrm{PIM}}(\lambda)=\frac{\sigma_{m}(\lambda)}{\rho_{m} \nu_{m}},
\end{gathered}
$$

in the simplest case. Thus the spectral mass-specific scattering cross section is simply the spectral particle scattering cross section normalized to the particle mass if there is only one type and size of mineral particle in suspension. And if the particle mass happens to be $1.0 \times 10^{-12} \mathrm{~g}$, reasonable for a clay particle, the particle scatter cross section, $\sigma_{m}(\lambda)$, will be numerically equal to the mass-specific normalized particle scatter cross section, $\sigma_{\mathrm{PIM}}(\lambda)$. Bohren and Huffman [29] emphasize that the mass-specific scattering cross section of a particle is one of the fundamental 
optical parameters in the interaction of a particle with an electromagnetic field. We note here that an increase in size of the assumed single type of mineral particle, as reflected in an increase in $\nu_{m}$ in Eq. (6), will cause a decrease in $\sigma_{\mathrm{PIM}}(\lambda)$. Conversely a decrease in size of the assumed mineral particle will result in an increase in $\sigma_{\text {PIM }}(\lambda)$. Furthermore a relatively large particle will exhibit no spectral slope in the mass-specific scattering cross section because the particle scattering coefficient will have no spectral slope. Smaller particles will, of course, demonstrate a spectral slope in the mass-specific scattering cross section.

We must note that the relationships between the dry organic matter POM and the optical properties of suspended organic particles, assumed of one size and type, are strictly analogous to the abovedelineated relations for an assumed single type of suspended mineral particle, but they are not identical. The determination of PIM, with due regard for the structural water relations of clay minerals, results in a mineral residue with known density [5]. However, the determination of the POM by dry weight of suspended matter filtered from a seawater sample and differencing it with the ash weight of the suspended matter is a determination of only the organic mass component of the suspended organic particle. The water component of the suspended organic particle is driven off in the drying step. Thus the POM volatiles cannot be related directly to $\rho_{0}$, the wet weight density of the suspended organic matter. Wet weight density of organics is related to dry organic matter density by

$$
\rho_{o}=\rho_{\mathrm{do}} f_{\mathrm{do}}+\rho_{w} f_{w},
$$

where $\rho_{\text {do }}$ is the dry organic mass density of the organic particle, $f_{\mathrm{do}}$ is the volume fraction of dry organic matter in the organic particle, $\rho_{w}$ is the density of water, and $f_{w}$ is the volume fraction of water in the organic particle. The mass-specific scattering cross section for POM is then

$$
\sigma_{\mathrm{POM}}(\lambda)=\frac{\sigma_{o}(\lambda)}{\rho_{\mathrm{do}} f_{\mathrm{do}} \nu_{o}} .
$$

In analogy with the relations for a suspended mineral particle, $\sigma_{\mathrm{POM}}(\lambda)$ is the organic particle scattering cross section, $\sigma_{o}(\lambda)$, normalized to the dry organic mass of the suspended particle. In the case of the organic particle, we can also state that an increase in the size of the particle will result in a decrease in the value for $\sigma_{\mathrm{POM}}(\lambda)$, while a decrease in the size of the organic particle will result in an increase in the value for $\sigma_{\mathrm{POM}}(\lambda)$ if $f_{\text {do }}$ does not change. The tone of the above derivations for optical relations of mineral and organic particles was strongly inspired by the work of Bricaud and Morel [31].

It is rare to find suspended mineral and organic particles existing in just one size class, one exception being a heavy bloom of a single phytoplankton spe- cies. The major classes of suspended particles exist in PSDs. If we consider organic and mineral matter as the two major classes of suspended particles, we start to generalize Eqs. (6) and (7) with the particle densities for the two major classes. For suspended mineral particles, then, Eq. (6) becomes

$$
\sigma_{\mathrm{PIM}}(\lambda)=\frac{1}{\rho_{m}} \sum_{i} \sum_{j} \frac{\left[\sigma_{m}(\lambda)\right]_{i j}}{\left(v_{m}\right)_{i j}},
$$

or

$$
\sigma_{\mathrm{PIM}}(\lambda)=\frac{1}{\rho_{m}} \sum_{i} \sum_{j} \frac{\left[\sigma_{m}(\lambda)\right]_{i j}\left(N_{m}\right)_{i j}}{\left(V_{\mathrm{Tm}}\right)_{i j}}
$$

where $\rho_{m}$ is the average density of all mineral matter and the summations are over the $i$ th mineral species and the $j$ th size class, or volume, of that mineral species. The relative contribution of each component in the summations is then a function of the size distribution associated with each component. However, the densities of the suspended organic particles will vary depending on the concentration of water in the organic particle. Thus Eq. (7) for suspended organic particles becomes

$$
\sigma_{\mathrm{POM}}(\lambda)=\frac{1}{\rho_{\mathrm{do}}} \sum_{i} \sum_{j} \frac{\left[\sigma_{o}(\lambda)\right]_{i j}}{\left(f_{\mathrm{do}}\right)_{i j}\left(\nu_{o}\right)_{i j}},
$$

or

$$
\sigma_{\mathrm{POM}}(\lambda)=\frac{1}{\rho_{\mathrm{do}}} \sum_{i} \sum_{j} \frac{\left[\sigma_{o}(\lambda)\right]_{i j}\left(N_{o}\right)_{i j}}{\left(f_{\mathrm{do}}\right)_{i j}\left(V_{\mathrm{To}}\right)_{i j}} .
$$

The reasoning applied to the organic fraction of the suspended matter, again, is analogous but not identical with that applied to the mineral fraction of the suspended particulates. The organic dry density, $\rho_{\mathrm{do}}$, applied in Eqs. (10) and (11), is nearly constant. However, its role in Eqs. (10) and (11) is modified by its volume fraction, $f_{\text {do }}$, contribution to the density of the entire organic particle. In theory the volume fraction of dry organic matter in the particle can vary $[5,32]$ from possibly 0.2 to 1.0 . As yet there are no direct observations of organic particles containing virtually no water, so the volume fraction is probably closer to the lower end of the theoretical range. There is, then, at least one more variable in the description of the mass-specific scattering cross section of suspended organic particles than is the case with suspended mineral particles; this can increase the variability of organic mass-specific scattering cross sections. When considering the PSD of these components, the individual components each exhibit a lognormal distribution [33-35]. One method of summing the lognormal distributions of all component particles yields a PSD model containing two component particle types in the ocean [36-38]. The two 
component model proposes one particle component of small diameter, as with clay particles, and one component of larger diameter, such as algal cells or organic detritus. In coastal regions such a two component model can be tested by the mineral-organic component partition presented in Eqs. (8)-(11). In principle, then, the mass-specific spectral optical scattering cross sections provide valuable constraints, based on fundamental optical properties, on inferences regarding size distributions of the suspended matter. Various PSDs have been proposed for suspended matter [19] and all of these can be tested with the above-delineated relations.

We applied an average density of all the individual mineral particle species in Eqs. (ㅇ) and (9). The summation terms in those equations then give us a weighted mean particle scattering cross section and a weighted mean particle volume for a mean mineral particle. The concept of a mean particle to represent a PSD has a long history [39]. Determining a mean density for mineral particles is relatively easy-we calculate a mean mineral particle density, $\rho_{m}$, of $2.6 \pm 0.15 \times 10^{6} \mathrm{~g} \mathrm{~m}^{-3}$ from Babin et al. [5]. The situation for suspended organic particles is more complicated [5,32]. The volume of a cell can contain $80 \%$ water or more, while a particle of organic detritus probably contains much less water [5,32]. There are at least two possible average dry organic mass densities. Babin et al. [5] and Morel and Ahn [40] determined an organic dry mass density for algal organic matter of $1.38 \times 10^{6} \mathrm{~g} \mathrm{~m}^{-3}$ from data in [32]. However, much of the suspended POM is degradation products from living cells. We propose an average dry mass density for detrital organic matter from the average of the dry densities for cellulose [32]: $1.48 \pm 0.15 \times 10^{6} \mathrm{~g} \mathrm{~m}^{-3}$. The algal dry mass density value could be used in studies of ocean areas where it is known that living cells are a dominant component of the organic mass, and the organic detrital dry mass density could be used in studies of areas where organic detritus is dominant. The two densities can be utilized in situations where the partitioning of the organic mass is known.

We can investigate the bulk optical properties of the marine hydrosol when we have knowledge of the individual particle optical properties and their averages. For example, Gordon and Du [28], utilizing the discrete dipole approximation, were able to calculate the particle spectral scattering cross section of the double crenulated disk-shaped calcium carbonate lith plates of the coccolithophore Emiliana huxleyi. Coccolithophores are a very important component of the phytoplankton of the open ocean and often the nearshore waters $[11,41]$. There is great interest in the contribution of $\bar{E}$. $\overline{h u} x l e y i$ to the oceanic carbon budget. The aggregations of lith plates from coccolithophore blooms are visible in satellite images, so they are a significant factor in the optical properties of the marine hydrosol. We can predict the mass-specific scattering coefficient of small detached liths in the open ocean utilizing the Gordon and Du
[28] results and Eq. (6). We used $2.71 \times 10^{6} \mathrm{~g} \mathrm{~m}^{-3}$ for the density of $\mathrm{CaCO}_{3}, 0.616 \mu \mathrm{m}^{3}$ for the average volume of a lith plate, and the spectral particle cross sections calculated by Gordon and Du [28] and illustrated in their Fig. 7. The mass-specific mineral scattering cross section of a region of the open ocean dominated by detached liths from a coccolith bloom is shown in Fig. 1. This shows that the spectral massspecific scattering cross section of a small mineral particle such as a lith plate varies from $\sim 1.4 \mathrm{~m}^{2} \mathrm{~g}^{-1}$ in the blue end of the spectrum to $\sim 0.6 \mathrm{~m}^{2} \mathrm{~g}^{-1}$ in the red end of the spectrum. The value of $\sigma_{\mathrm{PIM}}(555) \approx$ $0.98 \mathrm{~m}^{2} \mathrm{~g}^{-1}$, approximately $60 \%$ of the numerical value of the lith plate particle scattering cross section. As previously noted, $\sigma_{m}(\lambda) \approx \sigma_{\mathrm{PIM}}(\lambda)$ for small mineral particles. The wavelength dependence of this optical parameter is $\lambda^{-n}$, where we determined $n$ to be approximately 1.8 . We expect the wavelength dependence to lessen as the particle increases in size.

Thus the mass-specific scattering cross section is simply the fundamental particle optical scattering cross section normalized by the mass of the mineral particle or the dry organic mass of an organic particle. There is the potential for the mass-specific scattering cross section to be used to invert remote sensing reflectance to determine the mass concentration of particulate matter [18]. However, the complexities of the coastal optical field are great [42], and much work will need to be done to effect this goal. In addition this optical parameter provides

\section{Mass-Specific Spectral Scattering Cross Sections Coccolith Plates: Medium Fishing Reel Model}

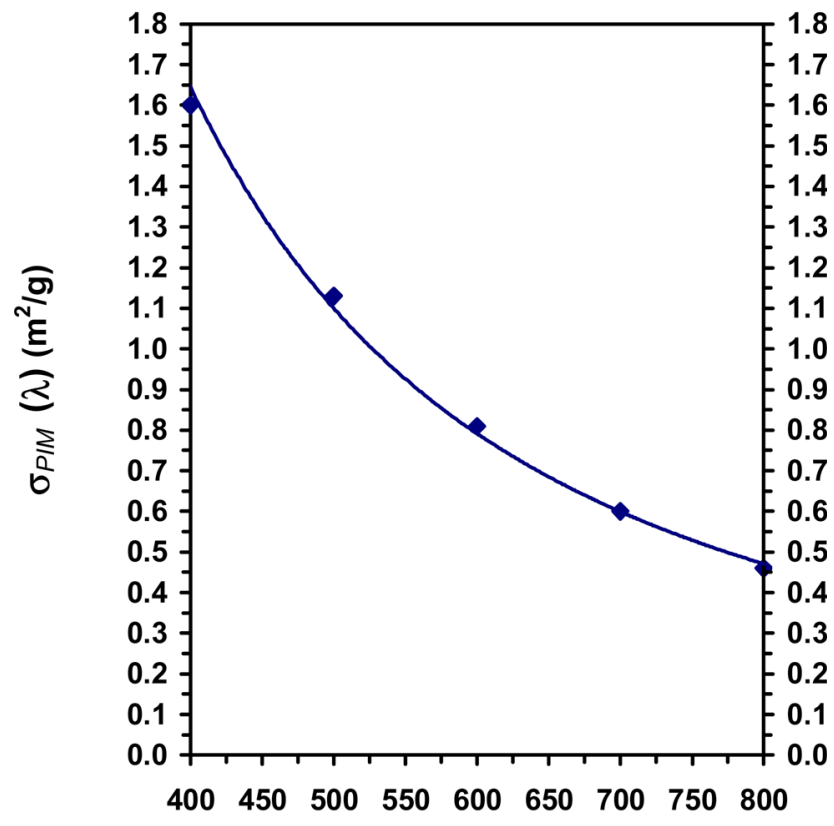

Wavelength $\mathbf{n m}$

Fig. 1. (Color online) Spectral mass-specific scattering cross sections of suspended coccolith lith plates from data and calculations of Gordon and $\mathrm{Du}[28]$. 
valuable constraints on attempts to determine the nature of PSDs that will be used to investigate the dynamics of particulates in the coastal ocean. There will be applications in the open ocean as well.

\section{Materials and Methods}

We have two sets of field data for this study, one collected at Mobile Bay, Alabama, 20-24 May 2002, by the Naval Research Laboratory-Stennis Space Center for a total of 24 field stations. The sampling area extended from inside Mobile Bay out to the coastal barrier islands: Dauphin Island and Petit Bois Island. The sampling stations followed the Mobile River sediment plume out of the bay and roughly along the coast and barrier islands ending up in open water. The other data set was collected at Southwest Pass, Mississippi River mouth, 29-30 July and 1-2 August 2003, by NASA-Stennis Space Center for a total of 16 field stations. The sampling stations extended from within Southwest Pass and the Mississippi River plume out to the Gulf of Mexico into relatively clear water. The samples were surface samples collected in the first $0.5 \mathrm{~m}$ of depth for possible future investigation of scattering properties and remote sensing algorithms.

The particulate scattering coefficient, $b_{p}(\lambda)$, was obtained for the two study areas with a WET Labs AC $9 \mathrm{~m}$ at wavelengths $412,440,488,510,532,555$, 650,676 , and $715 \mathrm{~nm}$. The AC-9s were attached to a CTD-rosette with several 61 Niskin bottles, which allowed the collection of water samples concurrent with the collection of $\mathrm{AC}-9$ data from the instrument attached to the rosette.

The concurrent water samples collected from the CTD-rosette were subjected to the standard gravimetric LOI technique [26] of filtering a water sample under vacuum onto a prewashed, preweighed glass fiber filter, drying, weighing, ashing, and weighing again. This protocol yields estimates of PIM and POM. The filters were of the $47 \mathrm{~mm}$ Whatman GF/F variety. Each stage of the technique is repeated until the weights obtained are constant. The filter and sample are initially dried at $103^{\circ} \mathrm{C}$ for $2 \mathrm{~h}$ and weighed to constancy. Then the sample is ashed at $550^{\circ} \mathrm{C}$ for $15 \mathrm{~min}$ and weighed to constancy. The initial weight provides total suspended solids (TSS) concentration and the ashed weight provides PIM concentration. The POM is obtained from the difference (TSS - PIM). An important aspect of the technique is to run process-control filters treated identically with sample filters except that deionized water is filtered rather than the water sample. Glass fiber filters tend to be fragile, and loss of filter mass during treatment must be accounted for [43]. Barillé-Boyer et al. [44] point out that the LOI method for determining POM has difficulties when inorganic matter is dominated by clay minerals. The ignition step drives off structural water from the clay mineral matrix, requiring correction factors for both the estimated mass of PIM and for the estimated mass of POM. Average clay mineral proportions for these samples were obtained from Doyle and Sparks [45] for Mobile Bay, Alabama, and Johnson and Kelley [46] for the mouth of the Mississippi River and the Barillé-Boyer, et al. [44] corrections then applied. Another source of error is salt retention by glass fiber filters. This will cause an overestimation of the TSS mass [47]. We have also recently determined that the salt retention on glass fiber filters is a function of the salinity of the sample-highly variable in coastal waters. We applied salt retention correction factors that we determined as a function of salinity.

We determined mineral and organic particle massspecific scattering cross sections by partitioning the total suspended particle spectral scattering coefficient, Eq. (4), using multiple linear regression with PIM and PŌM data. We have shown that the mineral spectral scattering coefficient, $b_{m}(\lambda)$, and the organic particle spectral scattering coefficient, $b_{o}(\lambda)$, can be expressed in terms of the mass-specific spectral scattering cross section and the total mass concentration of the particle type, Eqs. (5)-(7). The mass-specific scattering cross sections are, then, the partial regression coefficients or slopes of the multiple regression of $b_{p}(\lambda)$ with PIM and POM data [15, $\underline{48}-\underline{50]}$ :

$$
b_{p}(\lambda)=g(\lambda)+\sigma_{\mathrm{PIM}}(\lambda) \mathrm{PIM}+\sigma_{\mathrm{POM}}(\lambda) \mathrm{POM} .
$$

Equation (12) is a standard multiple regression equation that includes a term for the intercept, expressed here as $g(\lambda)$, on the dependent variable axis (particulate scattering coefficient axis) $[50,51]$. The $g(\lambda)$ intercept term is the value of $b_{p}(\lambda)$ when both $\mathrm{PIM}$ and $\mathrm{POM}=0$. Thus $g(\lambda)$ should not differ significantly from 0 . If this is not the case, the intercept value can give insight into possible problems with the determination of the PIM and POM values. The correlations, or strengths of association, between the variables of Eq. (12) were determined by Model I multiple linear regression [50-53]. However, least squares regression, or Model I-type regression, does not apply strictly to field data collected without direct control of independent variables by the investigator $[53,54]$. Correlations obtained in this way are valid, however [53]. Therefore Model II regression has been proposed for univariate regressions (one dependent variable and one independent variable) to obtain the best estimate of regression slopes from field observations not under direct experimental control $[53,54]$. The problem of obtaining the optimal regression slope becomes acute when there is relatively low, but still significant, correlation of the uncontrolled field variables adversely affecting the slope estimates [53]. This will show up in the attempt to obtain the estimates of $\sigma_{\mathrm{PIM}}(\lambda)$ and $\sigma_{\mathrm{POM}}(\lambda)$ from Model I multiple linear regression. Thus we propose here a generalization of Model II regression to the multivariate case to obtain the best estimates of $\sigma_{\mathrm{PIM}}(\lambda)$ and $\sigma_{\mathrm{POM}}(\lambda)$.

We will briefly describe the application of Model II regression to three variables, which is relevant to the effort to obtain the best slope or partial regression 
coefficient estimates for the mass-specific optical scattering cross sections. To simplify the extension of Model II regression to three variables, we express the equation in terms of principal components analysis and apply it first to the Model II regression of two variables, the well-known univariate regression, of a dependent variable, $y_{2}$, on an independent variable, $y_{1}$. We utilize the reduced major axis or geometric mean method throughout. Let $\bar{y}_{1}$ and $\bar{y}_{2}$ be the sample means, and $s_{1}$ and $s_{2}$ be the sample standard deviations of $y_{1}$ and $y_{2}$, respectively. Let $\mathbf{a}_{1}^{\prime}=\left(\begin{array}{c}a_{11}^{\prime} \\ a_{12}^{\prime}\end{array}\right)$ and $\mathbf{a}_{2}^{\prime}=\left(\begin{array}{c}a_{21}^{\prime} \\ a_{22}^{\prime}\end{array}\right)$ be the eigenvectors associated with the eigenvalues, $\boldsymbol{\lambda}^{\prime}=\left(\begin{array}{c}\lambda_{1}^{\prime} \\ \lambda_{2}^{\prime}\end{array}\right)$, of the correlation matrix, $\mathbf{R}=\left(\begin{array}{cc}1 & r_{12} \\ r_{21} & 1\end{array}\right)$, where $r_{12}$ is the correlation between $y_{1}$ and $y_{2}$. Then the Model II regression equation can be written as

$$
y_{2}=\left[\bar{y}_{2}+\left(\frac{s_{2}}{s_{1}}\right)\left(\frac{a_{21}^{\prime}}{a_{22}^{\prime}}\right) \bar{y}_{1}\right]+\left(\frac{s_{2}}{s_{1}}\right)\left(-\frac{a_{21}^{\prime}}{a_{22}^{\prime}}\right) y_{1},
$$

which has slope $\left(-\frac{a_{21}^{\prime}}{a_{22}^{\prime}}\right)\left(\frac{s_{2}}{s_{1}}\right)$. When using the correlation matrix for two variables, the magnitudes of the eigenvector components $a_{21}^{\prime}$ and $a_{22}^{\prime}$ will always be the same, and thus the slope estimator reduces to the reduced major axis estimator, $\pm \frac{s_{2}}{s_{1}}$.

The univariate equation can be extended to three variables as

$$
\begin{aligned}
y_{3}= & {\left[\left(\frac{a_{31}^{\prime}}{a_{33}^{\prime}}\right)\left(\frac{s_{3}}{s_{1}}\right) \bar{y}_{1}+\left(\frac{a_{32}^{\prime}}{a_{33}^{\prime}}\right)\left(\frac{s_{3}}{s_{2}}\right) \bar{y}_{2}+\bar{y}_{3}\right] } \\
& +\left(-\frac{a_{31}^{\prime}}{a_{33}^{\prime}}\right)\left(\frac{s_{3}}{s_{1}}\right) y_{1}+\left(-\frac{a_{32}^{\prime}}{a_{33}^{\prime}}\right)\left(\frac{s_{3}}{s_{2}}\right) y_{2},
\end{aligned}
$$

where $a_{i j}^{\prime}$ represents the $j$ th component of the $i$ th eigenvector from the correlation matrix, $\left(-\frac{a_{31}^{\prime}}{a_{33}^{\prime}}\right)\left(\frac{s_{3}}{s_{1}}\right)$ is the conditional slope associated with $y_{1}$, and $\left(-\frac{a_{32}^{\prime}}{a_{33}^{\prime}}\right)\left(\frac{s_{3}}{s_{2}}\right)$ is the conditional slope associated with $y_{2}$. Note that unlike the two variable case, the ratio of eigenvector elements will usually not equal 1 , and thus the slope estimates do not reduce to the ratio of sample standard deviations. Thus the optimum estimates of the mass-specific optical scattering cross sections, Eqs. (ㅁ) and (ㅁ), are

$$
\begin{aligned}
& \hat{\sigma}_{\mathrm{PIM}}(\lambda)=\left(-\frac{a_{31}^{\prime}}{a_{33}^{\prime}}\right)\left(\frac{s_{3}}{s_{1}}\right), \\
& \hat{\sigma}_{\mathrm{POM}}(\lambda)=\left(-\frac{a_{32}^{\prime}}{a_{33}^{\prime}}\right)\left(\frac{s_{3}}{s_{2}}\right),
\end{aligned}
$$

where $s_{3}$ is the standard deviation of $b_{p}(\lambda), s_{1}$ is the standard deviation of PIM, $s_{2}$ is the standard deviation of POM, and $a_{i j}^{\prime}$ represents the $j$ th component of the $i$ th eigenvector from the correlation matrix.

When we have the estimates of the mass-specific optical scattering cross sections, Eqs. (15) and (16), we are then able to partition the spectral particle scattering coefficient $b_{p}(\lambda)$ into the spectral scattering coefficient of mineral matter, $b_{m}(\lambda)$, and the spectral scattering coefficient of organic matter, $b_{o}(\lambda)$, at a given station. All that is required is to multiply the estimate of $\sigma_{\mathrm{PIM}}(\lambda)$ by PIM at a given station and multiply the estimate of $\sigma_{\mathrm{POM}}(\lambda)$ by POM at that station.

\section{Results}

The values of $b_{p}(\lambda)$, PIM, and POM for the two data sets were as follows. In Mobile Bay $b_{p}(\lambda)$ varied from 0.90 to $20.6 \mathrm{~m}^{-1}$ across the wavelength spectrum, PIM varied from 1.59 to $22.24 \mathrm{mg} \mathrm{l}^{-1}$, and POM varied from 0.17 to $3.08 \mathrm{mg} \mathrm{l}^{-1}$. In Southwest Pass $b_{p}(\lambda)$ varied from 0.58 to $11.4 \mathrm{~m}^{-1}$ across the wavelength spectrum, PIM varied from 0.05 to $9.53 \mathrm{mg} \mathrm{l}^{-1}$, and POM varied from 0.18 to $1.89 \mathrm{mg} \mathrm{l}^{-1}$.

We determined the Model I partial regression coefficients (slopes) for the two data sets and the strength of the association between the two independent variables, PIM and POM, and the dependent variable, $b_{p}(\lambda)$. The most highly correlated data set, the results from the Naval Research Laboratory Mobile Bay cruise, showed $0.86 \leq R^{2} \leq 0.94$ across the spectrum from 412 to $715 \mathrm{~nm}$ for the analysis including the 24 field stations. The data set of lower correlation, the results from the NASA Southwest Pass cruise, showed $0.58 \leq R^{2} \leq 0.68$ across the same spectrum for the analysis including the 16 field stations. The $F$-test of significance of these $R^{2}$ values resulted in $p$-values $<0.005$ for all wavelengths of Southwest Pass and even smaller $p$-values for Mobile Bay. In addition the individual Model I partial regression coefficients were investigated for statistical significance by a two-sided $t$-test at the 0.05 significance level [52]. The mineral and organic partial regression coefficients for Mobile Bay were significant at this level. For Southwest Pass, however, although the mineral partial regression coefficients were significant at this level, the organic partial regression coefficients were not statistically significant at the 0.05 level.

For Mobile Bay the Model I partial regression coefficients and standard errors for suspended mineral matter are plotted in Fig. 2 along with the Model II partial regression coefficients. The Model I and Model II coefficients track each other closely and the Model II partial regression coefficients sit comfortably inside the standard error limits of the Model I partial regression coefficients. Similar plots for the suspended organic matter of Mobile Bay are in Fig. 3. The partial regression coefficients for organic matter also track each other closely, and the Model II coefficients fall easily within the standard error limits of the Model I coefficients. The mineral Model II coefficients are uniformly larger than the 


\section{Northern Gulf of Mexico \\ Mobile Bay: May 2002}

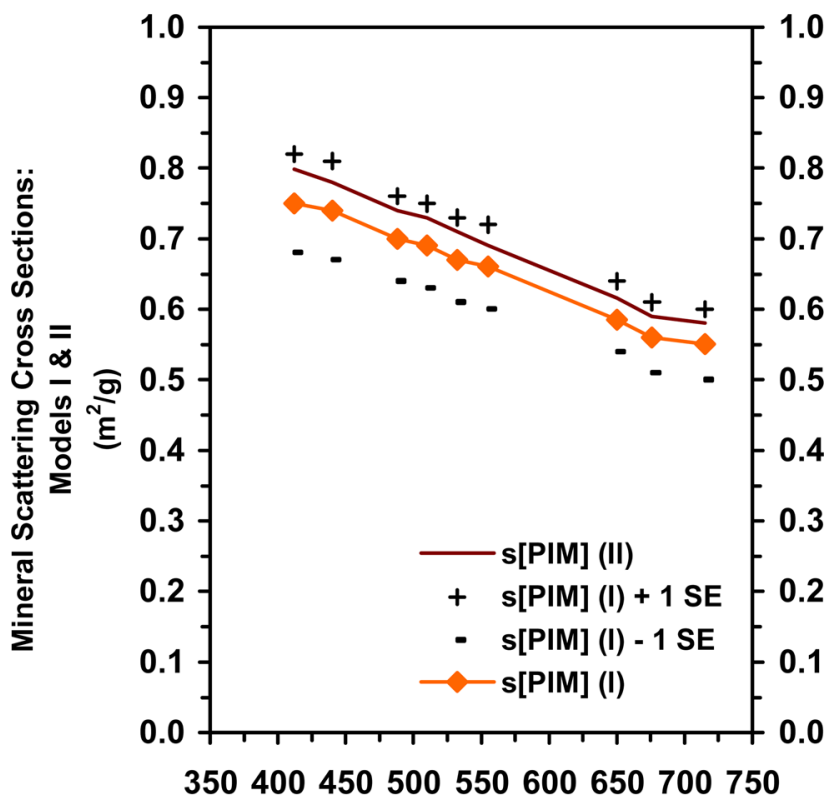

Wavelength $\mathbf{n m}$

Fig. 2. (Color online) Spectral mass-specific optical scattering cross sections of suspended mineral matter in Mobile Bay, Alabama. Model I-type multiple regression results with standard errors plotted along with the estimates from the Model II-type multiple regression. In the figure legend $\mathrm{s}[\mathrm{PIM}]$ represents $\sigma_{[\mathrm{PIM}]}$ and $\mathrm{s}$ $[\mathrm{POM}]$ represents $\sigma_{[\mathrm{POM}]}$.

\section{Northern Gulf of Mexico Mobile Bay: May 2002}

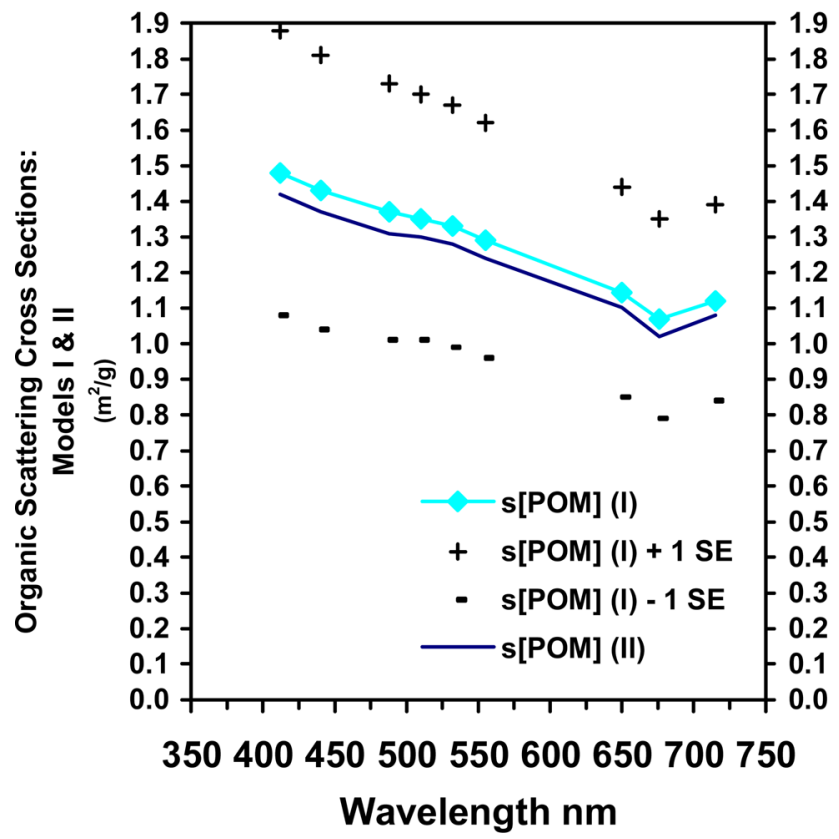

Fig. 3. (Color online) Spectral mass-specific optical scattering cross sections of suspended organic matter in Mobile Bay, Alabama. Model I-type multiple regression results with standard errors plotted along with the estimates from the Model II-type multiple regression. In the figure legend $\mathrm{s}[\mathrm{PIM}]$ represents $\sigma_{[\mathrm{PIM}]}$ and $\mathrm{s}$ $[\mathrm{POM}]$ represents $\sigma_{[\mathrm{POM}]}$. mineral Model I coefficients, while the organic Model II coefficients are uniformly smaller than the organic Model I coefficients.

At Southwest Pass the Model I partial regression coefficients and standard errors for suspended mineral matter are plotted in Fig. 4 along with the Model II mineral partial regression coefficients. The similar plots for the suspended organic matter of Southwest Pass are shown in Fig. 5. In this case the Model II mineral partial regression coefficients fall outside the standard error limits of the Model I mineral coefficients, are uniformly larger than the Model I coefficients, and show a spectral slope not evident in the Model I coefficients. The organic Model II partial regression coefficients lie within the broad standard error range of the Model I organic partial regression coefficients and are uniformly smaller than the Model I organic partial regression coefficients. The standard error limits of the Model I organic partial regression coefficients span zero for some of the wavelengths.

We partitioned the particle spectral scattering coefficients into spectral scattering coefficients for mineral particles and spectral scattering coefficients for organic particles, multiplying the mass concentration of mineral or organic matter at a particular field station by its respective mass-specific scattering cross section (partial regression coefficient). The partitioned particle spectral scattering coefficients for

\section{Northern Gulf of Mexico Southwest Pass: Summer 2003}

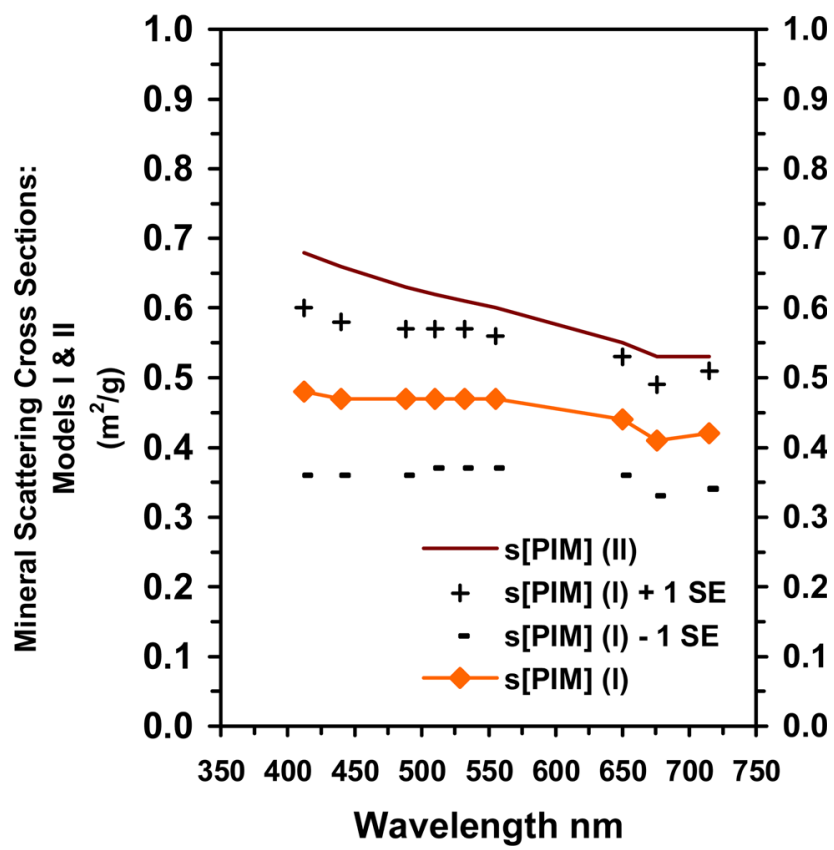

Fig. 4. (Color online) Spectral mass-specific optical scattering cross sections of suspended mineral matter at Southwest Pass, Mississippi River, Louisiana. Model I-type multiple regression results with standard errors plotted along with the estimates from the Model II-type multiple regression. In the figure legend s[PIM] represents $\sigma_{[\mathrm{PIM}]}$ and $\mathrm{s}[\mathrm{POM}]$ represents $\sigma_{[\mathrm{POM}]}$. 


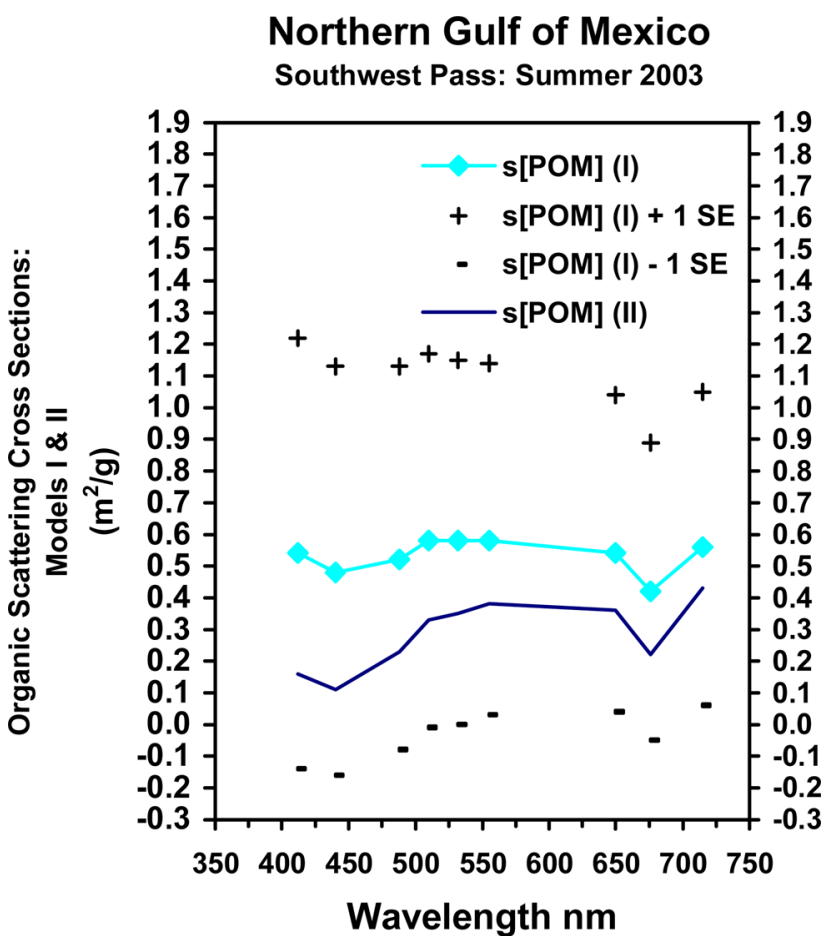

Fig. 5. (Color online) Spectral mass-specific optical scattering cross sections of suspended organic matter at Southwest Pass, Mississippi River, Louisiana. Model I-type multiple regression results with standard errors plotted along with the estimates from the Model II-type multiple regression. In the figure legend s[PIM] represents $\sigma_{[\mathrm{PIM}]}$ and $\mathrm{s}[\mathrm{POM}]$ represents $\sigma_{[\mathrm{POM}]}$.

Station 23-s01 in Mobile Bay are plotted in Fig. 6. The partitioned particle spectral scattering coefficients for Station AC3-13 at Southwest Pass are plotted in Fig. 7. In both field sites the particulate spectral scattering due to mineral scattering dominates the particulate organic spectral scattering: by a factor of 4 in Mobile Bay (see Fig. 6) and a factor of 20 to 30 at Southwest Pass (see Fig. 7).

We investigated the efficiency of the Model I and Model II spectral partial regression coefficients in reconstructing the spectral particle scattering coefficients at each station of the field exercises. The sum of the calculated mineral and organic spectral scattering coefficients should equal the particle spectral scattering coefficients measured at each station. A series of plots covers the ranges of particle concentrations utilized here. High particle concentration was defined as 6.87-22.24 $\mathrm{mg} \mathrm{l}^{-1}$ of PIM for Mobile Bay and 6.01-9.53 $\mathrm{mg} \mathrm{l}^{-1}$ of PIM for Southwest Pass. Medium particle concentration was defined as 5.00$6.86 \mathrm{mgl}^{-1}$ of PIM for Mobile Bay and 1.22$3.76 \mathrm{mg} \mathrm{l}^{-1}$ of PIM for Southwest Pass. Low particle concentration was defined as $1.59-4.65 \mathrm{mg} \mathrm{l}^{-1}$ of PIM for Mobile Bay and 0.05-1.12 $\mathrm{mgl}^{-1}$ of PIM for Southwest Pass. We defined the concentrations in terms of PIM because this material tended to dominate the scattering process in these coastal regions.

All stations relatively high in suspended mineral matter for Mobile Bay and Southwest Pass have the reconstructed spectral particle scattering curves
Particle Scatter: Station 22s01

Mobile Bay: May 2002

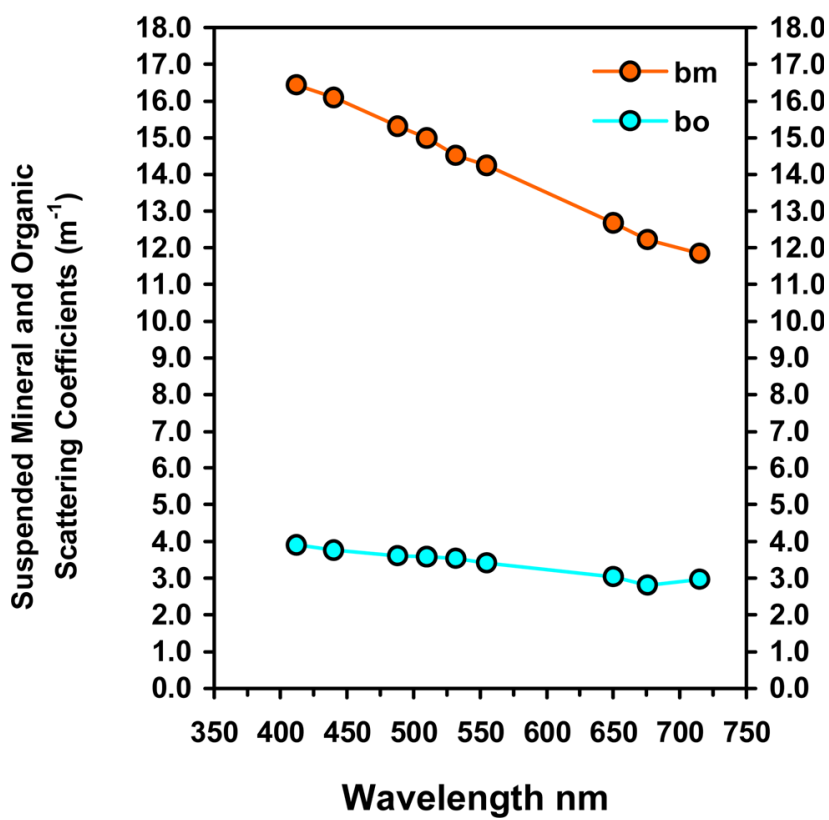

Fig. 6. (Color online) Partitioned total particle spectral scattering coefficient from station 23s01, Mobile Bay, Alabama. The suspended mineral spectral particle scattering coefficient $\left(b_{m}\right)$ and the suspended organic spectral particle scattering coefficient $\left(b_{o}\right)$ indicated.

Particle Scatter: Station AC3-13 Southwest Pass, Mississippi River

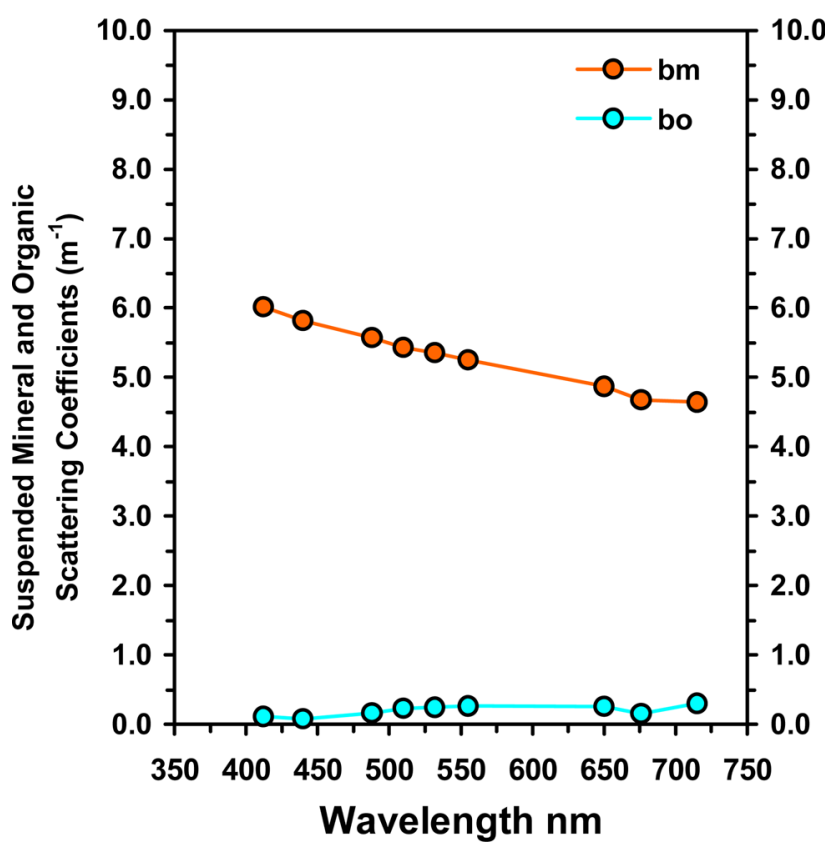

Fig. 7. (Color online) Partitioned total particle spectral scattering coefficient from station AC3-13, Southwest Pass, Mississippi River, Louisiana. The suspended mineral spectral particle scattering coefficient $\left(b_{m}\right)$ and the suspended organic spectral particle scattering coefficient $\left(b_{o}\right)$ indicated. 
plotted against the measured spectral particle scattering curves in Figs. 8 and 9, respectively. In Mobile Bay the spectral particle scattering curves reconstructed from Model II [see Fig. 8(a)] and Model I [see Fig. 8(b)] multiple regressions tend to agree, but the Model I reconstructions [see Fig. 8(b)] may deviate more from the measured spectral scattering coefficients than do the Model II reconstructions. All of the Model II curves agree closely with the measured spectral scattering values with the exception of two stations. In this case the maximum deviation from the field data curves was $25 \%$. At Southwest Pass the spectral particle scattering curves reconstructed from the Model II [see Fig. 9(a)] spectral particle scattering cross sections are in closer agreement with the field data at all stations but one [see Fig. 9(b)]. Here the maximum deviation of that Model II curve from the field data curve was $40 \%$.

All stations at a medium level of suspended mineral matter have their particle spectral scattering reconstructions from Model I and Model II plotted against the measured particle spectral scattering curves in Figs. 10 and 11. In Mobile Bay we see that the reconstructions of the particle spectral scattering curves from Model II [see Fig. 10(a)] and Model I [see Fig. 10(b)] are in close agreement in their relation to the measured particle scattering values. In both cases only three stations are not in close agreement with the measured spectral scattering coefficients. In this case the maximum deviation of the model curves

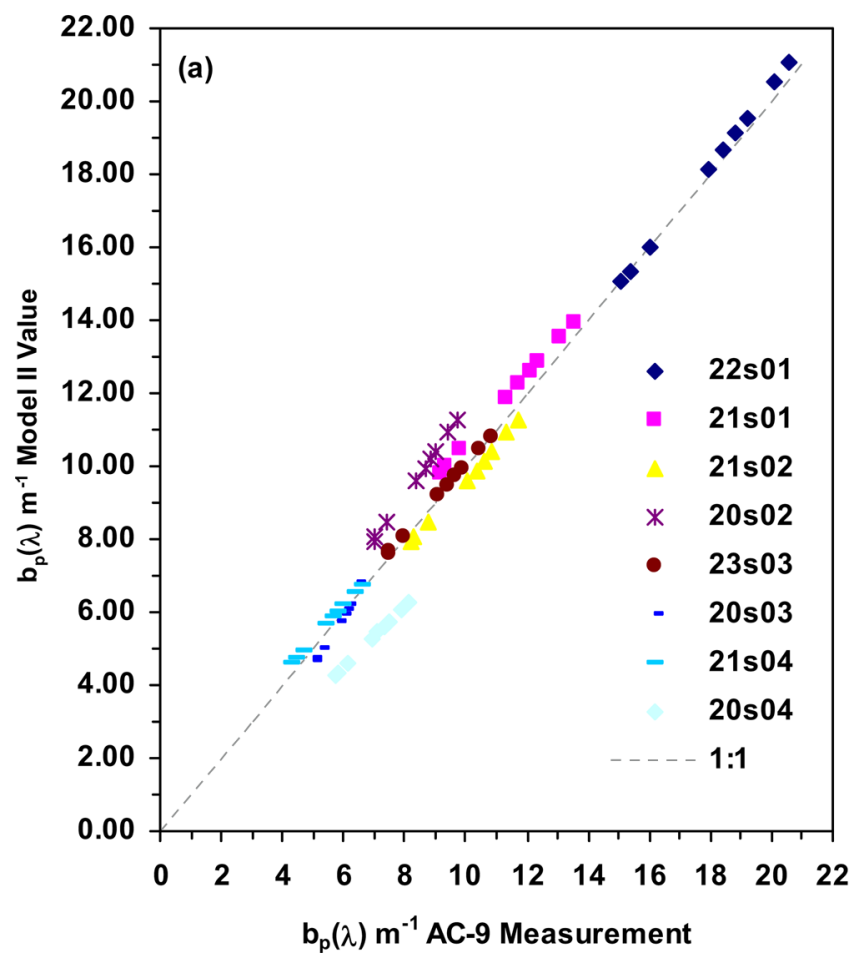

from the field data curves was $42 \%$. At Southwest Pass the Model II [see Fig. 11(a)] reconstructed curves are in closer agreement with the measured scattering values than the Model I [see Fig. 11(b)] curves. One station in Fig. 11(b) has Model II values not in close agreement with the field data. In this case the maximum deviation of the Model II curve from the field data curve was $50 \%$.

All stations relatively low in concentration of suspended mineral matter with particulate spectral scattering reconstructions from Model I and Model II are plotted against the measured values in Figs. 12 and 13. In Mobile Bay the Model II [see Fig. 12(a)] spectral particle scattering curve reconstructions are in better agreement with the measured values than the Model I [see Fig. 12(b)] values. The maximum deviation of the reconstructed curves from the field data curves [see Fig. 12(a)] was 20\%. At Southwest Pass the Model II [see Fig. 13(a)] reconstructed curves tend to show closer agreement with the field data curves with one exception. At this rather low concentration of suspended matter, the reconstructions are less efficient at tracking the measured values. The maximum deviation of the aberrant Model II curve from the field data ranges was $70 \%$.

\section{Discussion}

We have directly partitioned the spectral particle scattering coefficient with a Model II-type multiple

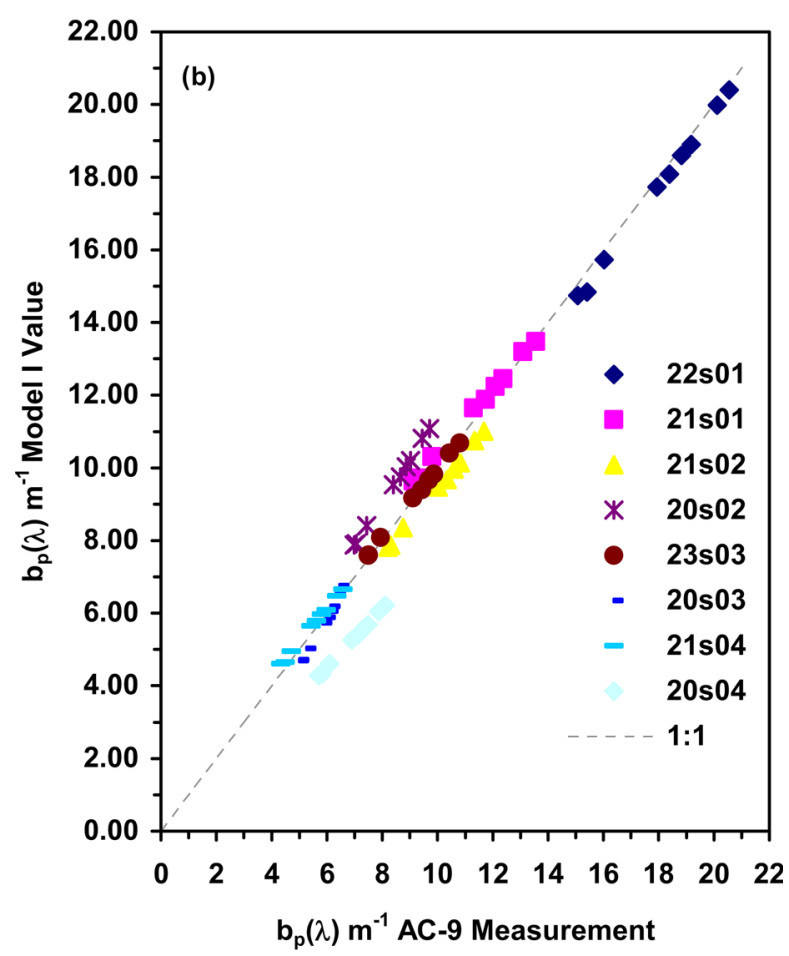

Fig. 8. (Color online) Comparison of particle spectral scattering coefficients for stations of high suspended mineral concentrations $\left(\mathrm{PIM}=6.87-22.24 \mathrm{mg} \mathrm{l}^{-1}\right)$, Mobile Bay, Alabama. Particle spectral scattering coefficients reconstructed from mass-specific spectral scattering cross sections and PIM and POM. (a) Reconstructed particle spectral scattering coefficients utilizing Model II-type mass-specific spectral scattering cross sections plotted against measured particle spectral scattering coefficients. (b) Reconstructed particle spectral scattering coefficients utilizing Model I-type mass-specific spectral scattering cross sections plotted against measured particle spectral scattering coefficients. 

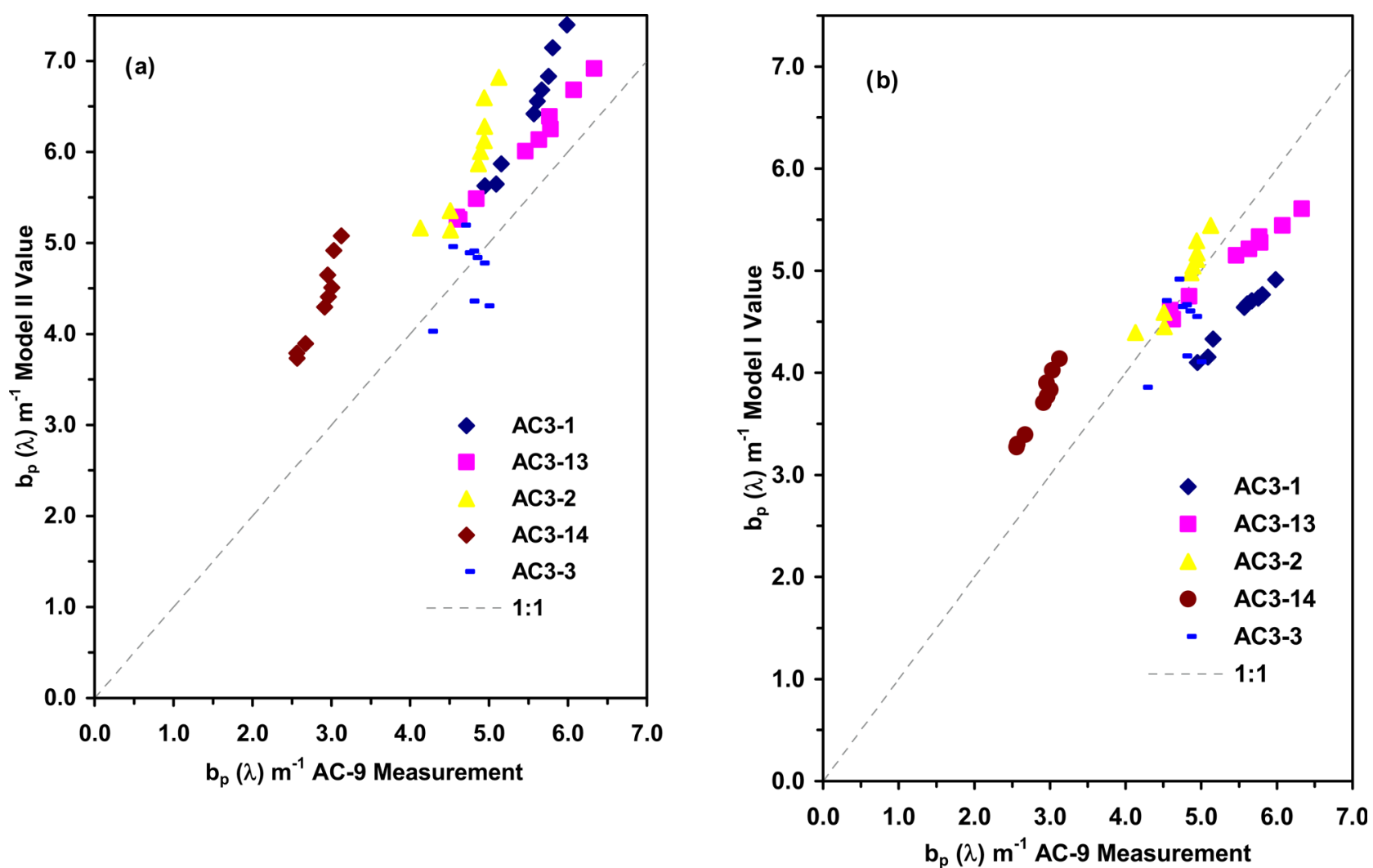

Fig. 9. (Color online) Comparison of particle spectral scattering coefficients for stations of high suspended mineral concentrations $\left(\mathrm{PIM}=6.01-9.53 \mathrm{mgl}^{-1}\right)$, Southwest Pass, Mississippi River mouth. Particle spectral scattering coefficients reconstructed from massspecific spectral scattering cross sections and PIM and POM. (a) Reconstructed particle spectral scattering coefficients utilizing Model II-type mass-specific spectral scattering cross sections plotted against measured particle spectral scattering coefficients. (b) Reconstructed particle spectral scattering coefficients utilizing Model I-type mass-specific spectral scattering cross sections plotted against measured particle spectral scattering coefficients.

regression method utilizing measured data relevant to the theory of particle scattering. This multiple regression generates mass-specific scattering cross sections, which can then be used to determine the scattering coefficient for both suspended minerals and organic particulates. The mass-specific scattering cross section converts the mass concentration of mineral or organic matter to the scattering coefficient of suspended minerals or suspended organic matter. In addition we have demonstrated that the mass-specific scattering cross section is a simple function of the fundamental optical properties of the suspended particles, and it thus provides information about the nature of the suspended particles themselves. The mass-specific scattering cross sections determined in this way are statistical averages and subject to the limitations of the method of derivation and calculation.

The multiple regression method of determining the mass-specific scattering cross sections of mineral and organic matter rests on a few assumptions. We presume, for example, that suspended mineral matter has the same composition at each station and the only difference between stations is that the concentration varies, not the composition. Thus the suspended mineral matter is simply "diluted" or "concentrated" in a conservative manner between stations. If the composition does vary, the mass-specific cross sections determined are spatial averages over various compositions of suspended mineral matter, and the mass-specific scattering cross section would not necessarily apply strictly to a given station. Furthermore significant layering of particle types will impact the analysis similarly. Partitioning the stations and depths into meaningful groupings of materials will allow separate multiple regression analyses and the mass-specific scattering cross sections can then be compared. A strong gradient in the variables always helps in a regression analysis, and we had this in these data sets. If there is significant phytoplankton growth over the period of sampling and the phytoplankton is the major component of the organic matter, the variation in the concentration of organic matter would not be conservative, and this would adversely affect the interpretation of any mass-specific organic scattering cross sections determined.

The mass-specific spectral scattering cross sections (spectral partial regression coefficients) for Model I-type and Model II-type multiple regressions from Mobile Bay are comparable (see Figs. 2 and 3 ). This is assured by the relatively high correlations of 

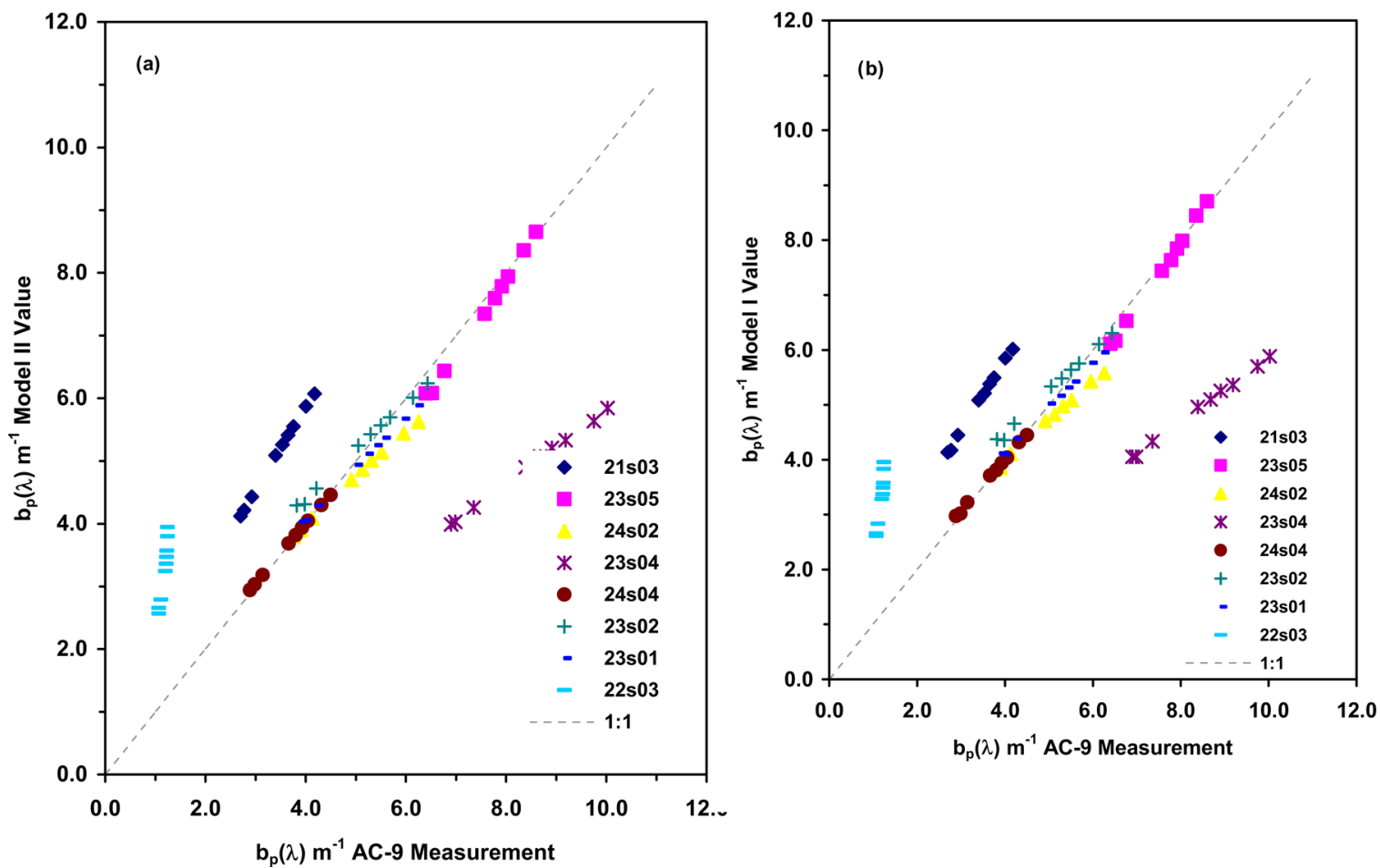

Fig. 10. (Color online) Comparison of particle spectral scattering coefficients for stations of medium suspended mineral concentrations $\left(\mathrm{PIM}=5.00-6.86 \mathrm{mg} \mathrm{l}^{-1}\right)$, Mobile Bay, Alabama. Particle spectral scattering coefficients reconstructed from mass-specific spectral scattering cross sections and PIM and POM. (a) Reconstructed particle spectral scattering coefficients utilizing Model II-type mass-specific spectral scattering cross sections plotted against measured particle spectral scattering coefficients. (b) Reconstructed particle spectral scattering coefficients utilizing Model I-type mass-specific spectral scattering cross sections plotted against measured particle spectral scattering coefficients.

the Mobile Bay data $[\underline{53}, \underline{55}]$. A very high correlation would probably show essentially no difference between the spectral optical scattering cross sections determined by either method of multiple regression. An interesting trend shown in Figs. 2 and 3 is that the Model II-type estimates for the mass-specific mineral spectral scattering cross sections are greater than the Model I-type estimates while the opposite is true for the mass-specific spectral scattering cross sections for organic matter. In the univariate regression (one dependent variable and one independent variable) it is known that the Model II regression slope is greater than the Model I regression slope $[53,55]$. However, we see a new trend arising in the Model II-type multivariate regression. The Model II partial regression slope for organic matter, the second independent variable, is less than the Model I partial regression slope-to our knowledge this has not been previously reported for Model II regressions.

The estimate of mass-specific spectral scattering cross sections for Southwest Pass (see Figs. $\underline{4}$ and 5) came out differently because of the lower correlations of the spectral particle scattering coefficient and the mineral and organic concentrations. Here the Model II mineral mass-specific spectral scattering cross sections were also greater in magnitude than the Model I estimates; however, they were located outside the standard error band of the Model
I estimates (see Fig. 4). These Model II estimates for Southwest Pass are comparable in magnitude to the Model II estimates for Mobile Bay, and these Model II estimates also exhibit a spectral slope that is not evident in the Model I mineral mass-specific scattering estimates for Southwest Pass (see Figs. $\underline{2}$ and $\underline{4}$ ). Thus Model II multiple regression exhibits aspects of the data from Southwest Pass that are lost in the Model I multiple regression. The Model II estimates of the suspended organic spectral optical scattering cross sections lie below the Model I estimates of the spectral optical scattering cross sections but within the standard error limits. The variance of the spectral organic optical scattering cross sections is very high with estimates that occasionally span zero at the shorter wavelengths. It is not surprising that the Model II estimates fall within the large standard error band of the Model I spectral optical scattering cross sections - the very large variances of the organic scattering cross sections render them nonsignificant statistically. Recall the potential for large variances in organic mass-specific scattering cross sections indicated in Eqs. (10) and (11). The large variances come about by the variability of the water content of organic particles leading to greatly different densities of organic particles.

We did individual analyses for each day of the Mobile Bay data sampling period. There were more stations per day in the Mobile Bay data set, so better 

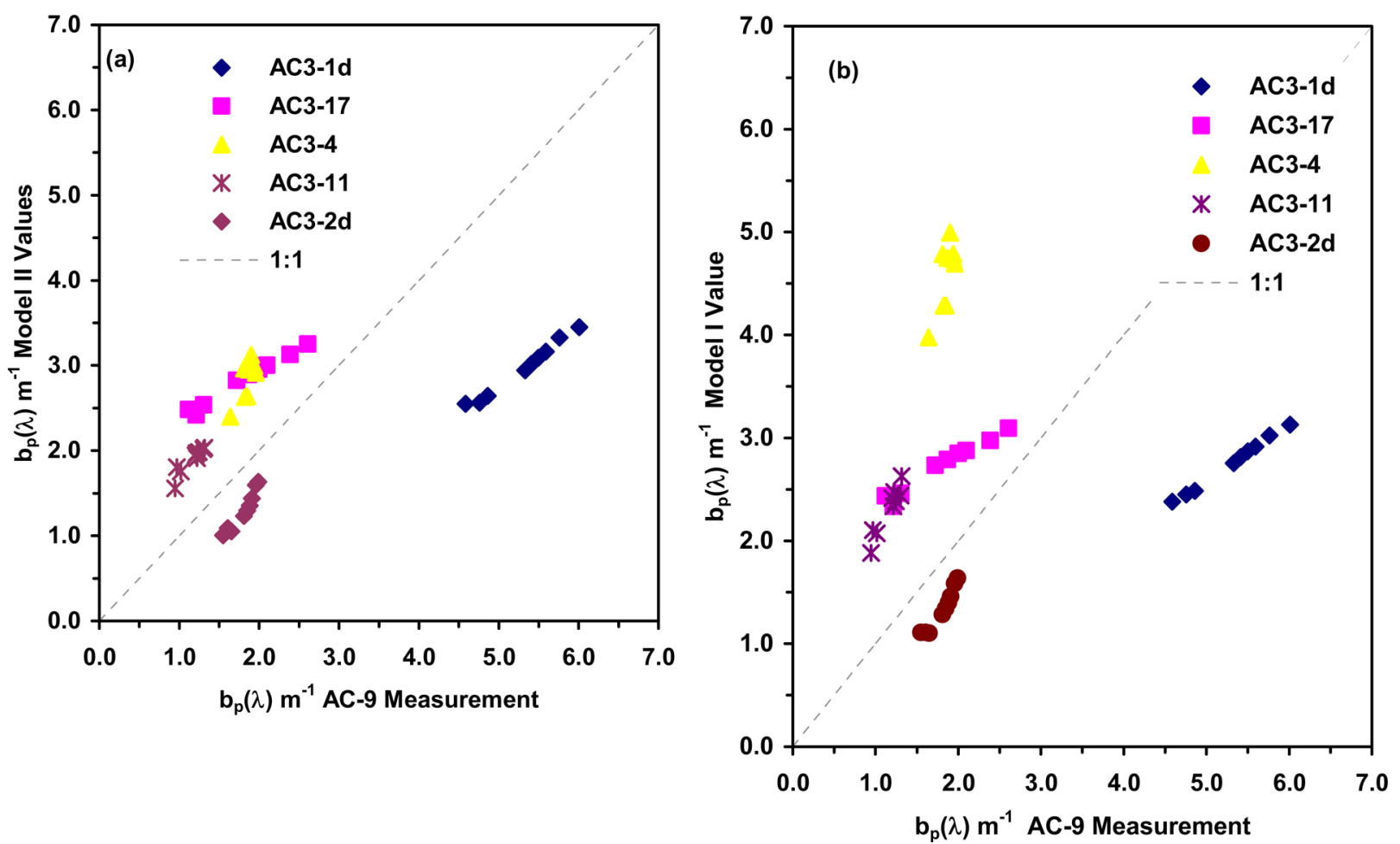

Fig. 11. (Color online) Comparison of particle spectral scattering coefficients for stations of medium suspended mineral concentrations $\left(\mathrm{PIM}=1.22-3.76 \mathrm{mgl}^{-1}\right)$, Southwest Pass, Mississippi River mouth. Particle spectral scattering coefficients reconstructed from massspecific spectral scattering cross sections and PIM and POM. (a) Reconstructed particle spectral scattering coefficients utilizing Model II-type mass-specific spectral scattering cross sections plotted against measured particle spectral scattering coefficients. (b) Reconstructed particle spectral scattering coefficients utilizing Model I-type mass-specific spectral scattering cross sections plotted against measured particle spectral scattering coefficients.

statistical conclusions could be drawn from them. The mass-specific scattering coefficients for mineral matter and organic matter on each day all overlapped the standard error limits established for the entire 24 station data set. The only difference was that in the analyses for each day, the organic massspecific scattering cross sections were often nonsignificant at the 0.05 level-the organic matter always having a larger standard error for the mass-specific coefficients than the suspended mineral matter. It would appear that the mineral matter did not change significantly in composition over the five-day period of sampling and the geographic sampling range of inside Mobile Bay out to the barrier islands. Organic matter, of course, will have greater opportunities to violate the assumption of conservative dilution or concentration that the mineral matter appears to follow. The conservative assumption would be violated with significant patchy or pulsating phytoplankton growth over an extended time period or an extended geographic range. Organic matter concentrations of primarily organic detritus would be expected to vary more conservatively.

We feel that the values reported and analyzed above are the first direct determinations of massspecific scattering cross sections obtained from measured field data of particulate scattering and mass concentrations of suspended mineral and organic particles. Earlier work had supplied plausible ap- proximations to the mass-specific scattering cross sections (often called mass-specific scattering coefficients), but their limitations made them approximations only and not direct determinations. For example, to obtain an approximation of $\sigma_{\mathrm{PIM}}(\lambda)$, the $b_{p}(\lambda)$ coefficient would be regressed directly against PIM [23] or $b_{p}(\lambda)$ would be regressed directly against TSS [5]. Thus no attempt is made to partition $b_{p}(\lambda)$ in either case or to partition TSS in the second case, so the contribution of suspended organic matter to the particle scattering coefficient is ignored in both cases and subsumed into the mineral particle scattering cross section. However, the regression of $b_{p}(\lambda)$ against TSS has also been assumed to be an estimate of $\sigma_{\mathrm{POM}}(\lambda)$ in open ocean waters away from coastal influence (subsuming the contribution of suspended minerals under organics) [5]. Furthermore the beam transmittance coefficient, $\bar{c}$, (the sum of the hydrosol absorption and scattering coefficients) has been assumed to be a measure of particle scattering and then regressed against TSS to provided approximations of $\sigma_{\mathrm{PIM}}(\lambda)$ or $\sigma_{\mathrm{POM}}(\lambda)$ depending on whether the water being sampled was coastal or open ocean [56]. The problems of confounding one major suspended component with another are obvious as we shall see.

Examples of the above-mentioned order-of-magnitude approximations come from Babin et al. [5] with a report of $\sigma_{\mathrm{PIM}}(555) \approx 0.5 \mathrm{~m}^{2} \mathrm{~g}^{-1}$ and $\sigma_{\mathrm{POM}}(555) \approx$ $1.0 \mathrm{~m}^{2} \mathrm{~g}^{-1}$ and essentially no or small spectral varia- 

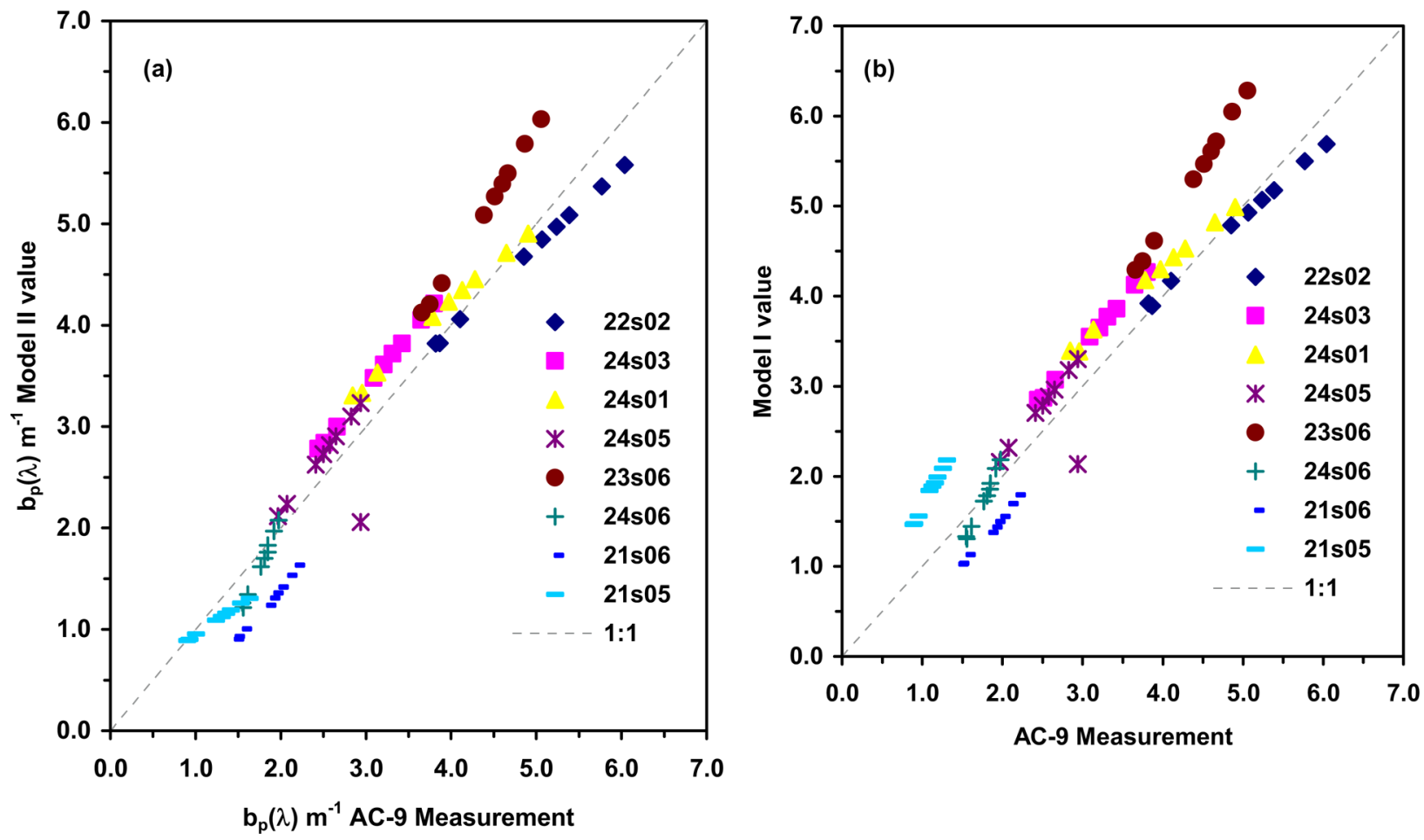

Fig. 12. (Color online) Comparison of particle spectral scattering coefficients for stations of low suspended mineral concentrations $\left(\mathrm{PIM}=1.56-4.65 \mathrm{mg} \mathrm{l}^{-1}\right)$, Mobile Bay, Alabama. Particle spectral scattering coefficients reconstructed from mass-specific spectral scattering cross sections and PIM and POM. (a) Reconstructed particle spectral scattering coefficients utilizing Model II-type mass-specific spectral scattering cross sections plotted against measured particle spectral scattering coefficients. (b) Reconstructed particle spectral scattering coefficients utilizing Model I-type mass-specific spectral scattering cross sections plotted against measured particle spectral scattering coefficients.
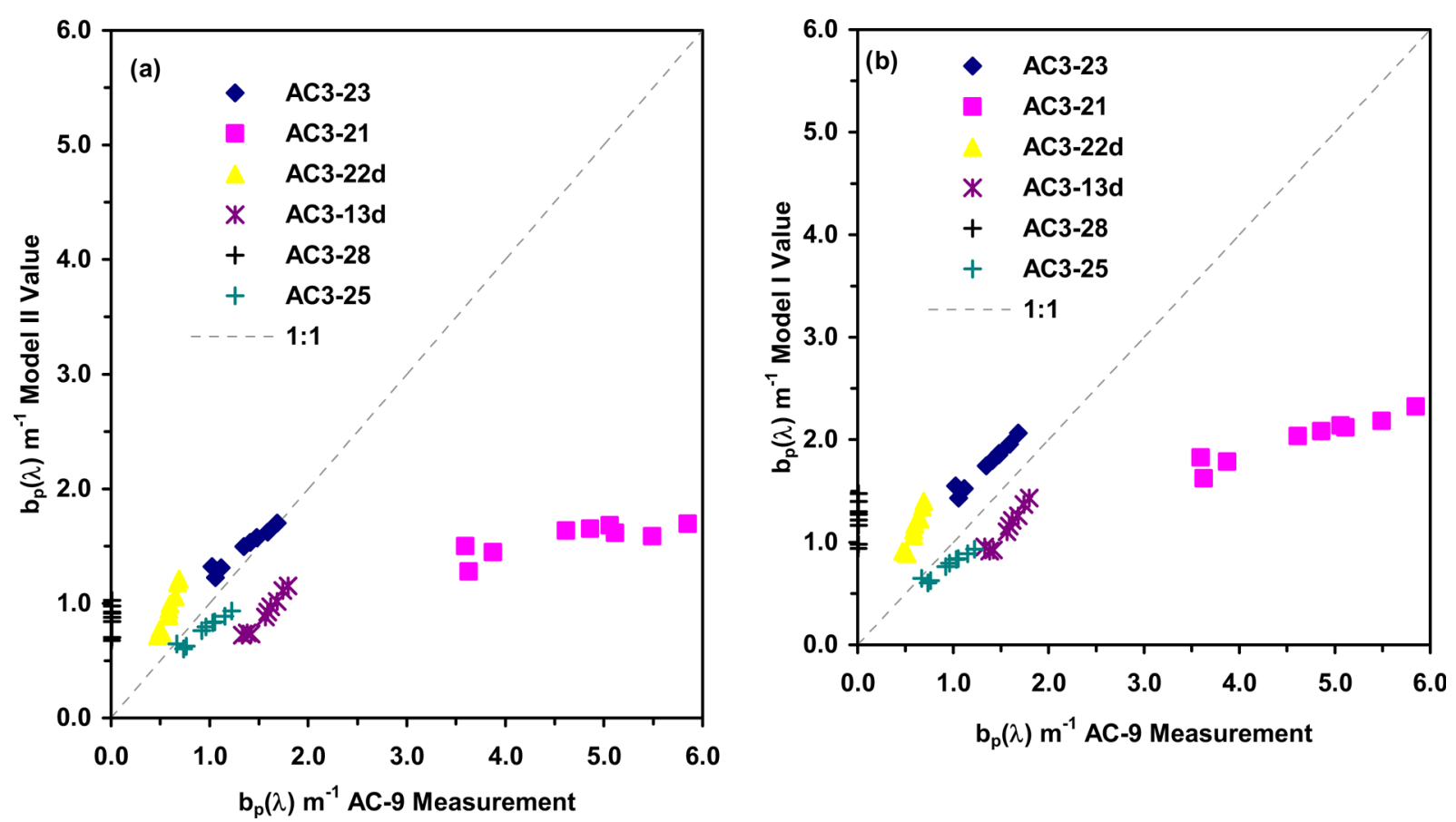

Fig. 13. (Color online) Comparison of particle spectral scattering coefficients for stations of low suspended mineral concentrations $\left(\mathrm{PIM}=0.05-1.12 \mathrm{mg} \mathrm{l}^{-1}\right)$, Southwest Pass, Mississippi River mouth. Particle spectral scattering coefficients reconstructed from massspecific spectral scattering cross sections and PIM and POM. (a) Reconstructed particle spectral scattering coefficients utilizing Model II-type mass-specific spectral scattering cross sections plotted against measured particle spectral scattering coefficients. (b) Reconstructed particle spectral scattering coefficients utilizing Model I-type mass-specific spectral scattering cross sections plotted against measured particle spectral scattering coefficients. 


\begin{tabular}{cl}
\hline Parameter & \multicolumn{1}{c}{ Value } \\
\hline$\lambda$ & Light wavelength in vacuum $(\mathrm{nm})$ \\
$b_{w}$ & Molecular water volume scattering coefficient $\left(\mathrm{m}^{-1}\right)$ \\
$b_{p}$ & Particle volume scattering coefficient $\left(\mathrm{m}^{-1}\right)$ \\
$b_{m}$ & Mineral particle volume scattering coefficient $\left(\mathrm{m}^{-1}\right)$ \\
$b_{o}$ & Organic particle volume scattering coefficient $\left(\mathrm{m}^{-1}\right)$ \\
$N_{m}$ & Number of mineral particles in a unit volume of seawater $\left(\right.$ number $\left.\mathrm{m}^{-3}\right)$ \\
$N_{o}$ & Number of organic particles in a unit volume of seawater $\left(\right.$ number $\left.\mathrm{m}^{-3}\right)$ \\
$\mathrm{PIM}$ & Dry weight per unit volume of seawater $\left(\mathrm{g} \mathrm{m}^{-3}\right)$ \\
$\mathrm{POM}$ & Dry weight per unit volume seawater $\left(\mathrm{g} \mathrm{m}^{-3}\right)$ \\
$\mathrm{TSS}$ & Particle dry weight per unit volume seawater $\left(\mathrm{g} \mathrm{m}^{-3}\right)$ \\
$f_{\mathrm{do}}$ & Volume of dry organic matter per unit volume of organic particle $($ dimensionless $)$ \\
$f_{w}$ & Volume of seawater per unit volume of organic particle $($ dimensionless $)$ \\
$\rho_{w}$ & Density of pure seawater $\left(\times 10^{6} \mathrm{~g} \mathrm{~m}^{-3}\right)$ \\
$\rho_{m}$ & Density of suspended mineral particles $\left(\times 10^{6} \mathrm{~g} \mathrm{~m}^{-3}\right)$ \\
$\rho_{o}$ & Density of suspended organic particles $\left(\times 10^{6} \mathrm{~g} \mathrm{~m}^{-3}\right)$ \\
$\rho_{\mathrm{do}}$ & Density of dry POM $\left(\times 10^{6} \mathrm{~g} \mathrm{~m} \mathrm{~m}^{-3}\right)$ \\
$\sigma_{m}$ & Scattering cross section for mineral particle $\left(\mathrm{m}^{2}\right.$ particle $\left.\mathrm{p}^{-1}\right)$ \\
$\sigma_{o}$ & Scattering cross section for organic particle $\left(\mathrm{m}^{2} \mathrm{particle}^{-1}\right)$ \\
$\sigma_{\mathrm{PIM}}$ & Mass-specific scattering cross section for mineral particle $\left(\mathrm{m}^{2} \mathrm{~g}^{-1}\right)$ \\
$\sigma_{\mathrm{POM}}$ & Mass-specific scattering cross section for organic particle $\left(\mathrm{m}^{2} \mathrm{~g}^{-1}\right)$ \\
$\nu_{m}$ & Volume of mineral particle $\left(\mathrm{m}^{3}\right)$ \\
$V_{\mathrm{Tm}}$ & Total volume of mineral particles per unit volume of seawater $($ dimensionless $)$ \\
\hline
\end{tabular}

tion in all waters investigated. Then Bowers and Binding [23] reported $\sigma_{\mathrm{PIM}}(555) \approx 0.4 \mathrm{~m}^{2} \mathrm{~g}^{-1}$ from investigations in the Irish Sea along with a peculiar drop in $\sigma_{\text {PIM }}(\lambda)$ in the blue region of the spectrum. It is possible to explain this by strong absorption in the blue region of the light spectrum as reported for some suspended minerals $[27,57]$, but the indirect determination of $b_{p}(\lambda)$ in their study remains a problem in this interpretation. Furthermore regressing PIM against the total particle scattering coefficient, $b_{p}(\lambda)$, confounds the organic scattering contribution to $b_{p}(\lambda)$ with the mineral contribution. We report $\sigma_{\mathrm{PIM}}(555) \approx 0.69 \mathrm{~m}^{2} \mathrm{~g}^{-1}$ in Mobile Bay and $\sigma_{\mathrm{PIM}}(555) \approx 0.60 \mathrm{~m}^{2} \mathrm{~g}^{-1}$ in Southwest Pass (see Figs. 2 and 4). Our results for $\sigma_{\mathrm{POM}}(555)$ indicate that it can be both higher and lower than $1.0 \mathrm{~m}^{2} \mathrm{~g}^{-1}$ (see Figs. 3 and 5). We demonstrate a spectral dependency for $\sigma_{\mathrm{PIM}}(\lambda)$ in both cases and $\sigma_{\mathrm{POM}}(\lambda)$ in Mobile Bay (see Figs. 2-4). However, in Southwest Pass $\sigma_{\mathrm{POM}}(\lambda)$ does not exhibit a spectral curve (see Fig. 5). The order-of-magnitude approximations reported by others are in rough accord with these direct determinations, but they lack the spectral detail we have been able to observe.

One major benefit of the mass-specific spectral scattering cross sections determined from multiple regression analysis of the particle spectral scattering coefficient and the mineral and organic matter concentrations is the ability to partition the spectral particle scattering coefficient into its components: the spectral scattering coefficient of suspended mineral matter and the spectral scattering coefficient of suspended organic matter. The spectral scattering coefficients for mineral matter and organic matter are shown in Figs. $\underline{6}$ and 7 , and they are different for Mobile Bay and Southwest Pass. In Mobile Bay the spectral scattering coefficient for mineral matter is approximately four times the value of the spectral scattering coefficient for organic matter. In Southwest Pass the mineral spectral scattering coefficient is approximately 20-30 times the value of organic matter. In either area the mineral contribution to total scattering is considerable (Mobile Bay) to an order-of-magnitude more (Southwest Pass) than the scatter contribution of suspended organic matter. Clearly the mineral matter will dominate the remote sensing signal and more so in the Southwest Pass. There are obvious implications here for remote sensing algorithms. The stations shown in Figs. 6 and 7 were at the maximum for suspended matter concentration and particle spectral scattering for each field sampling area so that the Mobile Bay stations had approximately three times as much suspended matter as the Southwest Pass stations. To our knowledge a direct determination of the spectral scattering coefficient for suspended organic matter in mineral dominated coastal areas has not been previously accomplished.

An important issue is the efficiency of our multiple regressions in reconstructing the field data curves of particle spectral scattering coefficients for individual sampling stations. The partitioned particle spectral scattering coefficients, determined for all stations of the two areas sampled, were used to reconstruct the particle spectral scattering coefficients. For those stations high in suspended matter concentration (see Figs. 8 and 9) the Model II reconstructions are good and comparable with the field data. The deviation of Model I reconstructions tends to be higher both for Mobile Bay and Southwest Pass [see Figs. 8(b) and 9(b)]. For stations of medium concentration of suspended matter (see Figs. 10 and 11), the reconstruc- 
tions are less efficient with Model II reconstructions generally better at both sample areas [see Figs. 10(a) and 11(a)]. At the low end of suspended particulate matter, the Model II reconstruction for Mobile Bay is quite good, the maximum deviation recorded being $20 \%$ [see Fig. 12(a)]. The reconstructions for Southwest Pass are adequate with Model II tending to closer agreement and one station considered aberrant [see Figs. 13(a) and 13(b)]. As we might expect from our discussions of Model I and Model II regressions, the relatively highly correlated values of Mobile Bay show reasonable agreement between the Model I and Model II reconstructions. In the Southwest Pass reconstructions, generated from relatively lower correlations, the Model I values consistently deviate more from the field data curves than the Model II reconstructions. So the multiple regressions utilized in this report are most efficient at reconstructing field data when the concentration of suspended matter is high and least efficient at very low concentrations. At the very low concentrations of suspended matter, we are approaching the limits of accuracy of the LOI technique and of the AC-9 meter. The water samples with the highest concentration of mineral matter in these studies contain significant amounts of clays. Isphording et al. [58] have pointed out that clays are predominant in Mobile Bay but are largely precipitated in the bay and do not make it out to the open water. It is quite likely that the qualitative composition of the low suspended matter stations differed from the qualitative composition of the high suspended matter stations. There was a greater number of low suspended matter stations at Southwest Pass. The general pattern was to encounter low suspended matter as we were further away from shore. This would encourage the flocculation and settling of mineral matter out of the water column and there would be a higher concentration of biogenic mineral matter: siliceous tests from diatoms and calcium carbonate liths from coccolithophores $[11,41]$. Biogenic mineral detritus is usually of larger diameter than minerogenic clays and would thus make a smaller contribution to the mass-specific mineral scattering cross section, Eq. (5). Thus the smaller mineral particles are to be expected for the high concentrations of PIM, and they will make the dominant contribution to the average mineral scattering cross section. This would explain the higher values of the reconstructed spectral scattering coefficients in the stations with a lower concentration of suspended mineral particles.

The other major benefit of determining the massspecific particle scattering cross sections is that we can make inferences about the nature and properties of the suspended particles in addition to partitioning the particle spectral scattering coefficient. We can make many simple predictions. For example, any spectral slope for both $\sigma_{\mathrm{PIM}}(\lambda)$ and $\sigma_{\mathrm{POM}}(\lambda)$ will be indicative of the domination of the particle suite by smaller particles since the mass-specific scattering cross sections are simply normalized particle scatter- ing cross sections. This is demonstrated from the calculation of the spectral mass-specific scattering cross section of coccolithophore liths, which can be considered a typical small mineral particle (see Fig. 1). A spectral slope to the scattering cross section of small particles is a general prediction of optical theory $[12,28-30]$. We pointed out earlier that considerations of the mean densities of the suspended particulates allow some simplification of the mass-specific scattering cross section functions. We proposed that the mean density of mineral matter is approximately $2.6 \times 10^{6} \mathrm{~g} \mathrm{~m}^{-3}$ and the mean dry density of particulate dry organic matter is approximately $1.48 \times$ $10^{6} \mathrm{~g} \mathrm{~m}^{-3}$ for organic detritus and $1.38 \times 10^{6} \mathrm{~g} \mathrm{~m}^{-3}$ for living organic particulates. So for particles of comparable size and scattering cross section, considering the relations of Eqs. (6) and (10), we expect the massspecific scattering coefficient for organic matter to be, at a minimum, twice that of the mineral particle. If the organic particles have a high concentration of water, the ratio would be even higher. This is also one of the general predictions from the studies of Babin et al. [5]. If the mass-specific scattering cross section for the two particle classes is the same, we may infer that the average organic particle is at least twice the volume of the mineral particle. The volume of the average organic particle would be even greater, relative to the average inorganic particle, if the massspecific scattering cross section of organic matter is less than that of the mineral particle. And, conversely, application of known optical properties for suspended particles allows the prediction of the massspecific scattering cross section for a known particle in the environment. We have already demonstrated this in connection with the optical properties determined by Gordon and $\mathrm{Du}$ [28] for suspended lith plates (see Fig. 1).

The simple above-considerations can be greatly expanded by important new work investigating the optical properties of suspended mineral matter both theoretically and experimentally $[24,27,57]$. The particle scattering cross section is a function of both particle size and the complex refractive index [29]. Woźniak and Stramski [24] have made theoretical investigations of the mass-specific scattering cross section considering variations in the real and imaginary parts of the complex refractive index and the size distribution. They assumed a Jungian size distribution for the suspended particles-questionable [19,37,38] but this does provide a qualitative approximation of particle suites dominated by either small or large particles. They reconfirmed the relations concerning particle size and the spectral slope of the massspecific scattering cross section. That is, relative increase in particle size causes a decrease in spectral slope. However, they also demonstrated a loss in spectral slope of a small particle dominated distribution, a relatively high mass-specific scattering cross section, if the particle has a significant absorption coefficient, a relatively large imaginary coefficient of the complex refractive index. In addition they de- 
monstrated that the magnitude of the mass-specific scattering cross section can decrease with a decrease in the real part of the complex refractive index with no change in spectral slope.

Consider the nature of the particles in Mobile Bay given the results of theoretical analyses, the Model II multiple regressions, and the latest experimental work $[14,57]$. The mineral particles in Mobile Bay (see Fig. 2) exhibit a spectral mass-specific scattering cross section that is in remarkable agreement with results of laboratory analysis of suspended clays reported by Stramski et al. [57]. Suspensions of illite and montmorillonite exhibit spectral slopes for the mass-specific scattering cross sections very similar to what we report for $\sigma_{\text {PIM }}(\lambda)$ calculated from the Model II multiple regression (see Fig. 2). They report $\sigma_{\mathrm{PIM}}(550) \approx 0.70-0.82 \mathrm{~m}^{2} \mathrm{~g}^{-1}$ for illite and montmorillonite, which compares with the $\sigma_{\mathrm{PIM}}(550) \approx$ $0.695 \mathrm{~m}^{2} \mathrm{~g}^{-1}$ that we report for Mobile Bay. The standard error for $\sigma_{\mathrm{PIM}}(550)$ at Mobile Bay easily encompasses the above-values reported by Stramski et al. [57]. In addition illite and montmorillonite are known common constituents of the suspended clays of the northern Gulf of Mexico $[45,46]$. Thus we have evidence for small, clay-size particles in the suspended mineral component of Mobile Bay. That the organic particles in Mobile Bay (see Fig. 3), with $\sigma_{\mathrm{POM}}(555) \approx 1.25 \mathrm{~m}^{2} \mathrm{~g}^{-1}$, are also relatively small is attested to by the spectral slope of the mass-specific spectral scattering cross section. The spectral slope for the organic mass-specific scattering cross sections compares favorably with the spectral slopes for the spectral scattering cross sections reported by Stramski et al. [14] for picophytoplankton. The value of $\sigma_{\mathrm{POM}}(555)$ reported here can be easily duplicated with the typical scattering cross sections and spherical equivalent diameters of picophytoplankton [14] substituted into Eq. (10) utilizing the mean organic matter densities reported here. With $\sigma_{\mathrm{POM}}(555)$ being about twice the magnitude of $\sigma_{\mathrm{PIM}}(550)$, it is possible that the mean volume of organic particles in Mobile Bay could be comparable to the mean volume of the mineral particles as would be the case with picophytoplankton and the density of the mineral particles being about twice the density of the organic particles as predicted from Eqs. (9) and (10) and the mean densities proposed in this paper.

In Southwest Pass the nature of the suspended particles is apparently indeterminate in the Model I multiple regression analysis. The mineral massspecific spectral scattering cross sections are substantially larger in the Model II analysis than in the Model I multiple regression analysis (see Fig. 4). This is evidence that the mineral particle size is substantially smaller in Southwest Pass than would be indicated by the Model I analysis. And further evidence for this is that there is clearly a spectral slope $[12,27,57,59]$ for the Model II mass-specific mineral spectral scattering cross sections while none is evident for Model I. The $\sigma_{\mathrm{PIM}}(550) \approx 0.60 \mathrm{~m}^{2} \mathrm{~g}^{-1}$ for Southwest Pass from Model II falls a bit below the values reported for illite and montmorillonite, but the spectral slope appears to be comparable. This could be evidence for a mineral array of small claysize particles at Southwest Pass with an admixture of claylike material of a real refractive index lower than that for illite and montmorillonite into the suspended clay particles [24,57]. The nature of the organic particles at Southwest Pass is indicated by the $\sigma_{\mathrm{POM}}(555) \approx 0.32 \mathrm{~m}^{2} \mathrm{~g}^{-1}$ (Model II), which is indicative of a suite of large particles. The lack of a spectral slope to the mass-specific scattering cross section of the organic particles mirrors the lack of a spectral slope to the scattering cross sections of large nanophytoplankton as reported by Stramski et al. [14]. The value of $\sigma_{\mathrm{POM}}(555)$ reported here is easily duplicated utilizing the spectral scattering cross sections and spherical equivalent diameters for typical nanophytoplankton [14] and Eq. (10) with the mean values of organic particle density proposed here. Additionally further evidence that the organic particles are large phytoplankton comes from the dips in the mass-specific spectral scattering coefficient at $425 \mathrm{~nm}$ and $676 \mathrm{~nm}$ (see Fig. 5) also reported in the theoretical calculations of Stramski et al. [14] illustrating the effects of anomalous dispersion [60] on phytoplankton scattering cross sections caused by phytoplankton absorption bands. It is worth keeping in mind that the uncertainty limits for the organic matter at Southwest Pass are rather wide.

\section{Conclusion}

In summary we have performed a successful partition of the spectral scattering coefficient at study sites in the northern Gulf of Mexico utilizing massspecific scattering cross sections. We have delineated the quantitative contribution of suspended mineral and organic matter to the particulate scattering coefficient. With this partition we add to the arsenal of optical tools for studying the ocean environment and the dynamics of the suspended particulates that play such a critical role in the elemental and biogeochemical cycles of the ocean. The total scattering coefficient and its partitions give us information about the suspended matter load and its major constituents. The mass-specific scattering cross sections have the real potential to give us information about the probable mean particle size, possibly the underlying size distributions, and the variations in the complex refractive index of the suspended particulates.

There are several reasons for the variations in the efficiency of the multiple regression analysis in reconstructing the particle spectral scattering coefficients from field data. We are proposing improvements to the efficiency and accuracy of this procedure. Given the dominance of suspended PIM in its effect on the particulate spectral scattering coefficient and therefore the remote sensing reflectance, we must obtain more information about the nature of this material in the coastal ocean. We need to know the percentile of the clay component of the suspended mineral matter in order to apply the 
Barillé-Boyer et al. [44] corrections in the most efficient manner. This can be done relatively easily and routinely with $\mathrm{x}$-ray diffraction analysis on the field samples collected from the CTD rosettes. In this study we were forced to deal with averages of clay composition over an entire region rather than having detailed knowledge of the clay composition of individual station samples. Qualitative characterization of living suspended POM is probably done as well as any particle characterization now being attempted $[6,13,14]$. However, there is still little knowledge of particulate organic detritus. For example, the relative water concentration of living and nonliving organic particulates is particularly sparse. Among possibilities for characterizing the detrital organic particulates are determining carbon isotope ratios for ascertaining whether detrital carbon particulates came from $\mathrm{C}_{3}$ or $\mathrm{C}_{4}$ plants. Thus the variance we observe in our present sets of data is due partly to optical differences that are not accounted for in the grossest determinations of PIM and POM. When individual samples can be ascertained to be of similar materials or of differing materials, it will then be possible to partition the results of a research cruise into groups of samples that would be utilized to generate more accurate mass-specific particle scattering cross sections. Other forms of multivariate analyses such as principle components analysis would help to group data on particulate scattering coefficients, PIM, and POM into discrete similar groups that could then be analyzed by the Model II multiple linear regression method.

The mass-specific cross sections that we can now obtain, averages of the two major suspended components, are certainly useful, but better and more accurate mass-specific cross sections will be forthcoming when the nature of suspended particulates is well categorized: quartz, opal, carbonates, clays, and the various forms of suspended organic matter. The biogeo-optical program continues work and efforts along the lines of multicomponent optical models started decades ago [18]. The efforts to improve the determination and characterization of mass-specific scattering cross sections all involve determining the nature of the individual components of the two major classes of suspended particulate matter. To this end it is encouraging that there is much activity in recent years to better characterize the optical properties of suspended mineral matter $[11,21,24,27,28,38,41,57]$ and suspended organic matter $[3,6, \overline{14}, 31,32,40, \overline{61}-$ 63]. The effort to fully characterize the optical properties of the significant optically active components in the sea has been termed the reductionist approach [57]. The complete solution of Eqs. (8)-(11) is definitely the purview of the reductionist approach. It is clear that the completion of the biogeo-optical program of ocean optics, the recognition and investigation of the optical effects of the major components of suspended particulates, requires the reductionist approach.
The SAS code used to determine the Model II partial regression coefficients may be obtained from Scott J. Richter.

R. H. Stavn acknowledges the valuable discussions on regression with C. C. Trees, Center for HydroOptics and Remote Sensing, San Diego State University. D. Stramski, Marine Physical Laboratory, Scripps Institution of Oceanography, University of California at San Diego, submitted a detailed, and most helpful, review of this manuscript. We acknowledge the valuable support of a Research Assignment Leave from the University of North Carolina at Greensboro; a National Research Council Research Associateship through NASA, Applied Sciences Directorate, Stennis Space Center; a summer fellowship from the American Society of Engineering Education through Naval Research Laboratory, Code 7323, Coastal and Marginal Seas Section, Stennis Space Center; the early support from ONR grant N00014-97-0812; and the Naval Research Lab Project 0601153N to R. W. Gould, Jr., Predicting Coastal Bio-optical Response to Atmospheric/ Oceanographic Forcing, Stennis Space Center.

\section{References}

1. R. W. Gould Jr., R. A. Arnone, and M. Sydor, "Absorption, scattering, and remote-sensing reflectance relationships in coastal waters: testing a new inversion algorithm," J. Coast. Res. 17, 328-341 (2001).

2. M. Sydor, R. W. Gould, R. A. Arnone, V. I. Haltrin, and W. Goode, "Uniqueness in remote sensing of the inherent optical properties of ocean water," Appl. Opt. 43, 2156-2162 (2004).

3. J. S. Cleveland, "Regional models for phytoplankton absorption as a function of chlorophyll $a$ concentration," J. Geophys. Res. 100, 13333-13344 (1995).

4. R. W. Gould Jr. and R. A. Arnone, "Three-dimensional modeling of inherent optical properties in a coastal environment: coupling ocean colour imagery and in situ measurements," Int. J. Remote Sens. 19, 2141-2159 (1998).

5. M. Babin, A. Morel, V. Fournier-Sicre, F. Fell, and D. Stramski, "Light scattering properties of marine particles in coastal and open ocean waters as related to the particle mass concentration," Limnol. Oceanogr. 48, 843-859 (2003).

6. R. E. Green, H. M. Sosik, and R. J. Olson, "Contributions of phytoplankton and other particles to inherent optical properties in New England continental shelf waters," Limnol. Oceanogr. 48, 2377-2391 (2004).

7. R. E. Green and H. M. Sosik, "Analysis of apparent properties and ocean color models using measurement of seawater constituents in New England continental shelf surface waters," J. Geophys. Res. 109, C03026, doi:10.1029/2003JC001977 (2004).

8. D. Antoine, A. Morel, and H. Claustre, "Some peculiarities of case 1 waters optical properties in the northwestern Mediterranean Sea," presented at the ASLO/TOS Ocean Research Conference, Honolulu, Hawaii, USA, 15-20 February 2004.

9. H. Claustre, A. Morel, S. B. Hooker, M. Babin, D. Antoine, K. Oubelkheir, A. Bricaud, K. Leblanc, B. Quéguiner, and S. Maritorena, "Is desert dust making oligotrophic waters greener?, Geophys. Res. Lett. 29, 1469, doi:10.1029/2001GL014056 (2002).

10. C. Moulin, C. E. Lambert, F. Dulac, and U. Dyan, "Control of atmospheric export of dust from North Africa by the North Atlantic oscillation," Nature 387, 691-694 (1997). 
11. W. M. Balch, P. M. Holligan, S. G. Ackleson, and K. J. Voss, "Biological and optical properties of mesoscale coccolithophore blooms in the Gulf of Maine," Limnol. Oceanogr. 36, 629-643 (1991).

12. R. W. Gould Jr., R. A. Arnone, and P. M. Martinolich, "Spectral dependence of the scattering coefficient in case 1 and case 2 waters," Appl. Opt. 38, 2377-2383 (1999).

13. H. Loisel and A. Morel, "Light scattering and chlorophyll concentration in case 1 waters: a reexamination," Limnol. Oceanogr. 43, 847-858 (1998).

14. D. Stramski, A. Bricaud, and A. Morel, "Modeling the inherent optical properties of the ocean based on the detailed composition of the planktonic community," Appl. Opt. 40, 2929-2945 (2001).

15. C. E. Binding, D. G. Bowers, and E. G. Mitchelson-Jacob, "Estimating suspended sediment concentrations in moderately turbid waters; the impact of variable particle scattering properties," Remote Sens. Environ. 94, 373-383 (2005).

16. C. E. Binding, D. G. Bowers, and E. G. Mitchelson-Jacob, "An algorithm for the retrieval of suspended sediment concentrations in the Irish Sea from SeaWiFS ocean colour satellite imagery," Int. J. Rem. Sens. 24, 3791-3806 (2003).

17. A. Cunningham, A. Dudek, and D. Mckee, "Comparison of satellite and surface measurements of water leaving radiance and seawater composition in an optically variable shelf sea," presented at the Eighth International Conference on Remote Sensing for Marine and Coastal Environments, Halifax, Nova Scotia, Canada, 17-19 May 2005.

18. R. P. Bukata, J. H. Jerome, K. Ya. Kondratyev, and D. V. Pozdnayakov, Optical Properties and Remote Sensing of Inland and Coastal Waters (CRC Press, 1995).

19. R. H. Stavn and T. R. Keen, "Suspended minerogenic particle distributions in high-energy coastal environments: optical implications," J. Geophys. Res. Oceans 109, C05005, doi:10.1029/ 2003JC002098 (2004).

20. T. R. Keen and R. H. Stavn, "Developing a capability to forecast coastal ocean optics: minerogenic scattering," in Proc. 6th International Conference on Estuarine and Coastal Modeling, M. Spaulding and A. Blumberg, eds. (ASCE Press, 2000), pp. 178-193.

21. M. Babin and D. Stramski, "Variations in the mass-specific absorption coefficient of mineral particles suspended in water," Limnol. Oceanogr. 49, 756-767 (2004).

22. J. T. O. Kirk, "Dependence of relationships between inherent and apparent optical properties of water on solar altitude," Limnol. Oceanogr. 29, 350-356 (1984).

23. D. G. Bowers and C. E. Binding, "The optical properties of mineral suspended particles: a review and synthesis," Estuar., Coast. Shelf Sci. 67, 219-230 (2006).

24. S. B. Woźniak and D. Stramski, "Modeling the optical properties of mineral particles suspended in seawater and their influence on ocean reflectance and chlorophyll estimation from remote sensing algorithms," Appl. Opt. 43, 3489-3503 (2004).

25. W. A. Snyder, R. A. Arnone, C. O. Davis, W. Goode, R. W. Gould, S. Ladner, G. Lamella, W. J. Rhea, R. Stavn, M. Sydor, and A. Weidemann, "Optical scattering and backscattering by organic and inorganic particulates in U.S. coastal waters," Appl. Opt. 47, 666-677 (2008)

26. S. R. Pearlman, H. S. Costa, R. A. Jung, J. J. McKeown, and H. E. Pearson, "Solids," in Standard Methods for the Examination of Water and Wastewater, A. D. Eaton, L. S. Clesceri, and A. E. Greenberg, eds. (American Public Health Association, 1995), Section 209, pp. 2-53-2-64.

27. D. Stramski, S. B. Woźniak, and P. Flatau, "Optical properties of Asian mineral dust suspended in seawater," Limnol. Oceanogr. 49, 749-755 (2004).
28. H. R. Gordon and T. Du, "Light scattering by nonspherical particles: application to coccoliths detached from Emiliania huxleyi," Limnol. Oceanogr. 46, 1438-1454 (2001).

29. C. F. Bohren and D. R. Huffman, Absorption and Scattering of Light by Small Particles (Wiley-Interscience, 1983).

30. E. J. McCartney, Optics of the Atmosphere. Scattering by Molecules and Particles (Wiley-Interscience, 1976).

31. A. Bricaud and A. Morel, "Light attenuation and scattering by phytoplanktonic cells: a theoretical modeling," Appl. Opt. 25, 571-580 (1986).

32. E. Aas, "Refractive index of phytoplankton derived from its metabolite composition,” J. Plankton Res. 18, 2223 (1996), Table VIII, p. 2341.

33. M. Jonasz and G. Fournier, "Approximation of the size distribution of marine particles by a sum of log-normal functions," Limnol. Oceanogr. 41, 744-754 (1996).

34. C. E. Lambert, C. Jehanno, N. Silverberg, J. C. Brun-Cottan, and R. Chesselet, "Log-normal distributions of suspended particles in the open ocean," J. Mar. Res. 39, 77-98 (1981).

35. K. Mahmoud, "Lognormal size distribution of particulate matter," J. Sediment. Petrol. 43, 1161-1166 (1973).

36. D. Risovic, "Two component model of the sea particle size distribution," Deep-Sea Research, Part I 40, 1459-1473 (1993).

37. D. Risovic, "Effect of suspended particulate-size distribution on the backscattering ratio in the remote sensing of seawater," Appl. Opt. 41, 7092-7101 (2002).

38. F. Peng and S. W. Effler, "Suspended minerogenic particles in a reservoir: light-scattering features from individual particle analysis," Limnol. Oceanogr. 52, 204-216 (2007).

39. J. B. Austin, "Methods of representing distribution of particle size," Industrial and Engineering Chemistry, Analytical Edition 11, 334-339 (1939).

40. A. Morel and Y.-H. Ahn, "Optical efficiency factors of freeliving marine bacteria: influence of bacterioplankton upon the optical properties and particulate organic carbon in oceanic waters," J. Mar. Res. 48, 145-175 (1990).

41. W. M. Balch, D. T. Drapeau, T. L. Cucci, and R. D. Vaillancourt, "Optical backscattering by calcifying algae: separating the contribution of particulate inorganic and organic carbon fractions," J. Geophys. Res. 104, 1541-1558 (1999).

42. M. Defoin-Platel and M. Chami, "How ambiguous is the inverse problem of ocean color in coastal waters?," J. Geophys. Res. Oceans 112, C03004, doi:10.1029/2006JC003847 (2007).

43. R. A. Feely, J. H. Trefry, and B. Monger, "Chapter 1. Particle sampling and preservation," in Marine Particles: Analysis and Characterization, D. C. Heard and D. W. Spencer, eds. (American Geophysical Union, 1991), pp. 5-22.

44. A.-L. Barillé-Boyer, L. Barillé, H. Massé, D. Razet, and M. Héral, "Correction for particulate organic matter as estimated by loss on ignition in estuarine ecosystems," Estuar., Coast. Shelf Sci. 58, 147-153 (2003).

45. L. J. Doyle and T. N. Sparks, "Sediments of the Mississippi, Alabama, and Florida (MAFLA) continental shelf," J. Sediment. Petrol. 50, 905-916 (1980).

46. A. G. Johnson and J. T. Kelley, "Temporal, spatial, and textural variation in the mineralogy of Mississippi river suspended sediment," J. Sediment. Petrol. 54, 67-72 (1984).

47. C. C. Trees, "Analytical analysis of the effect of dissolved solids on suspended solids determination," J. Water Pollut. Control Fed. 50, 2370-2373 (1978).

48. R. W. Gould Jr., R. H. Stavn, M. S. Twardowski, and G. M. Lamela, "Partitioning optical properties into organic and inorganic components from ocean color imagery," in Ocean Optics XVI, S. Ackleson and C. Trees, eds. (Office of Naval Research CDROM, 2002).

49. N. Jerlov, Marine Optics (Elsevier, 1975). 
50. O. J. Dunn and V. A. Clark, Applied Statistics: Analysis of Variance and Regression (John Wiley, 1974).

51. L. M. Mezei, Practical Spreadsheet Statistics \& Curve Fitting for Scientists and Engineers (Prentice-Hall, 1990).

52. B. F. J. Manly, Multivariate Statistical Methods: A Primer (Chapman \& Hall, 2005).

53. W. E. Ricker, "A note concerning Professor Jolicoeur's comments," J. Fish. Res. Brd. Can. 32, 1494-1498 (1975).

54. E. A. Laws and J. W. Archie, "Appropriate use of regression analysis in marine biology," Mar. Biol. 65, 13-16 (1981).

55. R. R. Sokal and F. J. Rohlf, Biometry. The Principles and Practice of Statistics in Biological Research (W. H. Freeman, 1969).

56. E. T. Baker and J. W. Lavelle, "The effect of particle size on the light attenuation coefficient of natural suspensions," J. Geophys. Res. 89, 8197-8203 (1984).

57. D. Stramski, M. Babin, and S. B. Woźniak, "Variations in the optical properties of terrigenous mineral-rich particulate matter suspended in seawater," Limnol. Oceanogr. 52, 2418-2433 (2007).
58. W. C. Isphording, F. D. Imsand, and R. B. Jackson, "Fluvial sediment characteristics of the Mobile River Delta," Trans. Gulf Coast Assoc. Geol. Soc. XIVI, 397-408 (1985).

59. M. Sydor and R. A. Arnone, "Effect of suspended particulate and dissolved organic matter on remote sensing of coastal and riverine waters," Appl. Opt. 36, 6905-6912 (1997).

60. H. C. van de Hulst, Light Scattering by Small Molecules (Dover, 1981)

61. D. Stramski and C. D. Mobley, "Effects of microbial particles on oceanic optics: a database of single-particle optical properties," Limnol. Oceanogr. 42, 538-549 (1997).

62. C. D. Mobley and D. Stramski, "Effects of microbial particles on oceanic optics: methodology for radiative transfer modeling and example simulations," Limnol. Oceanogr. 42, 550-560 (1997).

63. D. Stramski, E. Boss, D. Bogucki, and K. J. Voss, "The role of seawater constituents in light backscattering in the ocean," Prog. Oceanogr. 61, 27-56 (2004). 